\title{
Barriers and facilitators of adjuvant hormone therapy adherence and persistence in women with breast cancer: a systematic review
}

This article was published in the following Dove Press journal:

Patient Preference and Adherence

23 February 2017

Number of times this article has been viewed

\section{Zoe Moon \\ Rona Moss-Morris \\ Myra S Hunter \\ Sophie Carlisle \\ Lyndsay D Hughes}

Health Psychology Section, Department of Psychology, Institute of Psychiatry, Psychology \&

Neuroscience, King's College

London, London, UK
Correspondence: Lyndsay D Hughes Health Psychology Section, Department of Psychology, Institute of Psychiatry, Psychology \& Neuroscience, King's College London, 5th Floor Bermondsey Wing, Guy's Hospital, London SEI 9RT, UK

Email lyndsay.hughes@kcl.ac.uk
Purpose: Nonadherence to hormone therapy in breast cancer survivors is common and associated with increased risk of mortality. Consistent predictors of nonadherence and nonpersistence are yet to be identified, and little research has examined psychosocial factors that may be amenable to change through intervention. This review aimed to identify predictors of nonadherence and nonpersistence to hormone therapy in breast cancer survivors in order to inform development of an intervention to increase adherence rates.

Methods: Studies published up to April 2016 were identified through MEDLINE, Embase, Web of Science, PsycINFO, CINAHL and gray literature. Studies published in English measuring associations between adherence or persistence and any predictor variables were included. Eligible studies were assessed for methodological quality, data were extracted and a narrative synthesis was conducted.

Results: Sixty-one eligible articles were identified. Most studies focused on clinical and demographic factors with inconsistent results. Some evidence suggested that receiving specialist care and social support were related to increased persistence, younger age and increased number of hospitalizations were associated with nonadherence, and good patient-physician relationship and self-efficacy for taking medication were associated with better adherence. A small amount of evidence suggested that medication beliefs were associated with adherence, but more highquality research is needed to confirm this.

Conclusion: Some psychosocial variables were associated with better adherence and persistence, but the results are currently tentative. Future high-quality research should be carried out to identify psychosocial determinants of nonadherence or nonpersistence that are modifiable through intervention.

Keywords: breast cancer, adherence, persistence, hormone therapy

\section{Introduction}

Breast cancer is the most common cancer in the UK, with 150 women being diagnosed every day. ${ }^{1}$ Three quarters of breast cancers contain receptors for estrogen and are known as estrogen receptor positive $(\mathrm{ER}+)$. While breast cancer survival rates are increasing, it is still the second most common cause of death from cancer in women. ${ }^{1}$ To increase survival rates and reduce the risk of recurrence, many women with ER+ breast cancer are prescribed hormone therapy (HT), such as tamoxifen, or aromatase inhibitors (AIs), which block the effects of estrogen on cancer cells. Five to ten years of HT significantly reduces rates of cancer recurrence and mortality in women with ER+ early breast cancer. ${ }^{2,3}$ Despite significant clinical benefits, many women do not take HT as prescribed, which leads to a significantly increased risk of mortality and recurrence. ${ }^{4-6}$ 
Adherence to tamoxifen and AIs ranges from $65 \%$ to $79 \%$ and $72 \%$ to $80 \%$, respectively, but falls over the course of treatment to $\sim 50 \%$ by the fourth or fifth year. ${ }^{7-9}$ Furthermore, half of patients discontinue HT by 5 years, ${ }^{10,11}$ suggesting that a significant proportion of patients are not receiving the full clinical benefits of HT. An understanding of the mechanisms behind nonadherence would facilitate development of effective interventions, with a view to improving adherence and ultimately increasing the survival benefits associated with HT. Clinical and demographic factors may be useful as identifiable risk factors but cannot be modified through intervention. Psychosocial factors, however, are typically modifiable and are highly suitable targets for intervention. For example, illness and medication perceptions, such as necessity and concern beliefs, are predictive of adherence in other illnesses ${ }^{12,13}$ and have been successfully modified. ${ }^{14,15}$

A previous review of HT adherence and persistence concluded that little was known about the impact of clinical, demographic, or psychological factors and highlighted a need to research modifiable factors. ${ }^{16} \mathrm{~A}$ significant amount of research has been published since 2012, warranting an upto-date review. In 2015, Cahir et al ${ }^{17}$ carried out a systematic review of modifiable determinants of adherence with a view to developing behavioral interventions. Although the review was useful, there were several limitations, which are addressed by the current review. First, the main conclusions were that side effects, the number of prescription medications and the type of practitioner (general practitioner [GP] vs oncologist) influenced HT adherence or persistence. These factors are mostly not suitable for behavior change intervention. A more targeted review of modifiable psychosocial predictors would provide further guidance for the development of an intervention. Second, as gray literature databases and conference abstracts were not included in the search, some key studies are missing from Cahir et al's review. Finally, the authors conducted a meta-analysis, but due to significant heterogeneity, only a very small proportion of studies could be included, limiting the value of the results. For example, although 13 studies investigated the effects of the number of prescription medications, only four studies were eligible for the meta-analysis. Therefore, a narrative synthesis may be more appropriate. Van Liew et a ${ }^{18}$ conducted a narrative synthesis concluding that social support, patient-centered interactions, anxiety and medication beliefs were reliably associated with adherence or persistence. However, this review conducted a limited search of only two databases and may have missed some important eligible studies. Furthermore, empirical interest in this area is growing and a considerable number of studies have been published in the 2 years since the previous reviews.

The current review aims to build upon and address limitations in the previous reviews and identify factors related to HT adherence or persistence by:

(1) conducting an updated and broader search to ensure that all relevant articles are identified;

(2) searching gray literature databases to identify unpublished literature;

(3) combining modifiable psychosocial factors with demographic, clinical and health care factors to provide a comprehensive overview of nonadherence and nonpersistence in this population; and

(4) conducting a narrative synthesis as opposed to a metaanalysis, due to the anticipated significant heterogeneity within the included studies.

\section{Methods}

\section{Search strategy}

The review was conducted in accordance with PRISMA guidelines. ${ }^{19}$ The following databases were searched from inception to April 2016: MEDLINE, Embase, Web of Science; PsycINFO and CINAHL. Search terms included a combination of terms related to, 1) breast cancer, 2) nonadherence or nonpersistence, and 3) HT. Specific search terms are listed in Table S1. Reference lists of included articles were screened, and gray literature databases were searched.

\section{Study selection}

Inclusion/exclusion criteria are shown in Table 1. Participants had to be female, $>18$ years of age and prescribed adjuvant HT for primary breast cancer. Studies had to be conducted in clinical practice, as adherence rates are often higher in clinical trials. ${ }^{20}$ After removing duplicates, one author (ZM)

Table I Inclusion and exclusion criteria for studies in the review

\begin{tabular}{|c|c|}
\hline Inclusion criteria & Exclusion criteria \\
\hline $\begin{array}{l}\text { Patients were all female and } \\
\text { aged }>18 \text { years }\end{array}$ & $\begin{array}{l}\text { Articles not in the English language or } \\
\text { where the full text was not available }\end{array}$ \\
\hline $\begin{array}{l}\text { Patients had been prescribed } \\
\text { adjuvant HT to treat }\end{array}$ & $\begin{array}{l}\text { Studies including only DCIS or } \\
\text { stage IV patients }\end{array}$ \\
\hline primary breast cancer & Studies using an intervention to \\
\hline Studies had to be conducted & improve adherence \\
\hline in clinical practice & Studies investigating initiation to $\mathrm{HT}$ \\
\hline $\begin{array}{l}\text { Studies had to present } \\
\text { statistical tests of association } \\
\text { between HT adherence or } \\
\text { persistence and a correlate } \\
\text { or predictor }\end{array}$ & Studies not providing primary data \\
\hline
\end{tabular}

Abbreviations: DCIS, ductal carcinoma in situ; $\mathrm{HT}$, hormone therapy. 
screened titles and abstracts and excluded irrelevant articles. Full texts were then screened for inclusion by two authors (ZM and SC) using a predefined screening table, and one disagreement was resolved. Authors of conference abstracts were contacted to identify unpublished articles, and two authors responded with the full-text articles.

\section{Data extraction}

Information was extracted on study design, participant characteristics, adherence measurement, outcome measures and study results. Data were extracted by one researcher. Another researcher independently extracted data from $10 \%$ of articles, and there were no disagreements.

\section{Quality assessment (QA)}

The QA tool was adapted from Pasma et $\mathrm{al}^{21}$ based on recommendations from Sanderson et al. ${ }^{22}$ Studies were assessed on methods for selecting study participants and measuring study variables, appropriate statistical analyses, loss to follow-up and removal of nonpatient-initiated nonadherence (eg, due to contraindications). Studies scored 1 if they met each criterion and 0 if it was not met or was unclear. The proportion of criteria met was indicated by a percentage, as some criteria were not applicable for all articles. One author (ZM) conducted QA, and another author (SC) verified a random subset of $10 \%$ of articles. An additional author (LDH) resolved one discrepancy.

\section{Results}

A total of 6,140 articles were identified, and after removing duplicates and screening titles and abstracts, 120 full-text articles were screened. Sixty-one articles were included in the review (Figure 1). There was heterogeneity between studies in terms of outcome measures, type of effect sizes, definitions of adherence and predictor variables. It is, therefore, inappropriate to conduct a meta-analysis.

\section{Characteristics of studies}

The majority of studies were conducted in North America $(\mathrm{n}=34)$ and Europe $(\mathrm{n}=17$; Table 2$)$. The mean sample size was 3,042 (range 82-26,179), and there were 181,793 unique participants. Two studies included data analyzed

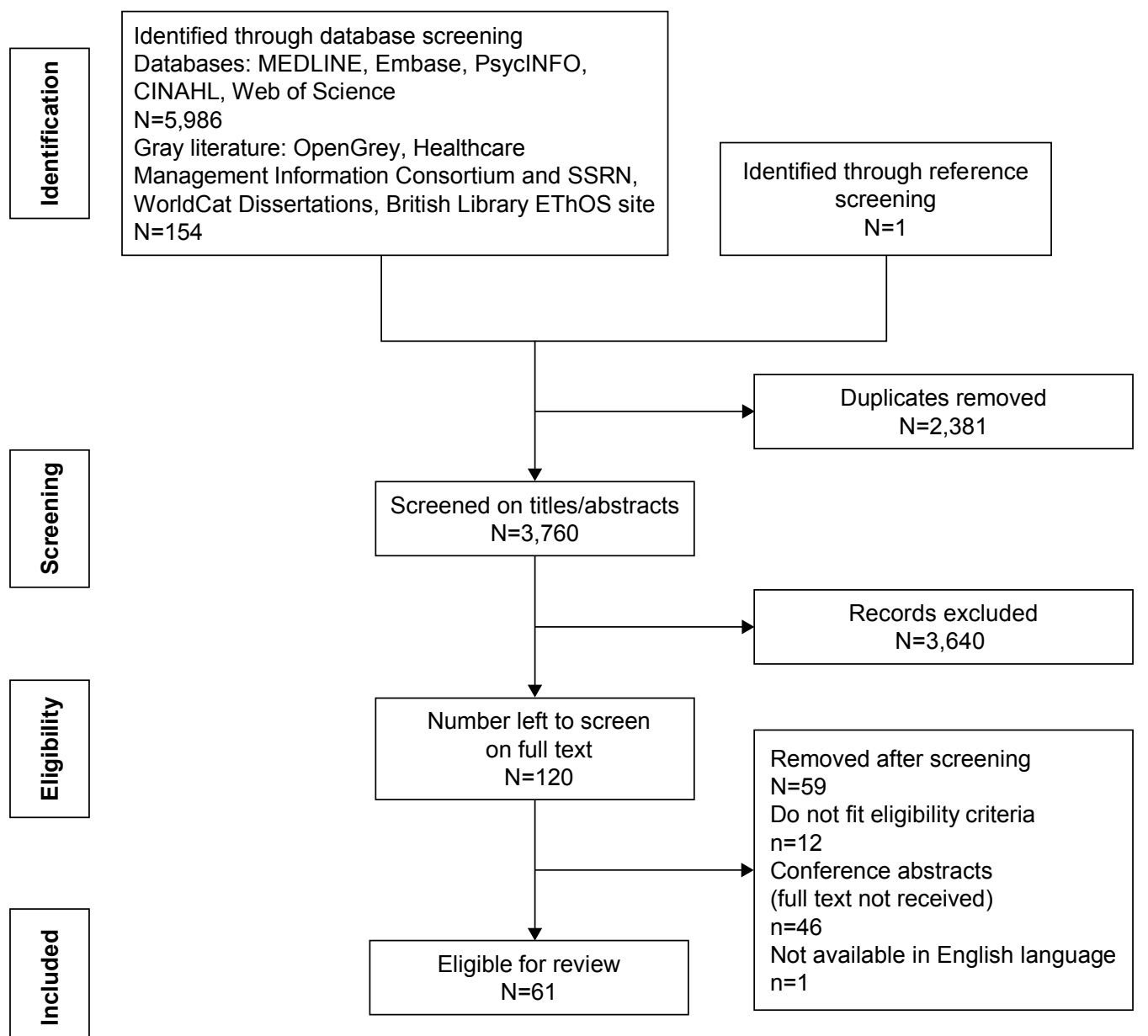

Figure I Flow diagram showing results of search strategy.

Abbreviations: HT, hormone therapy; SSRN, social science research network. 


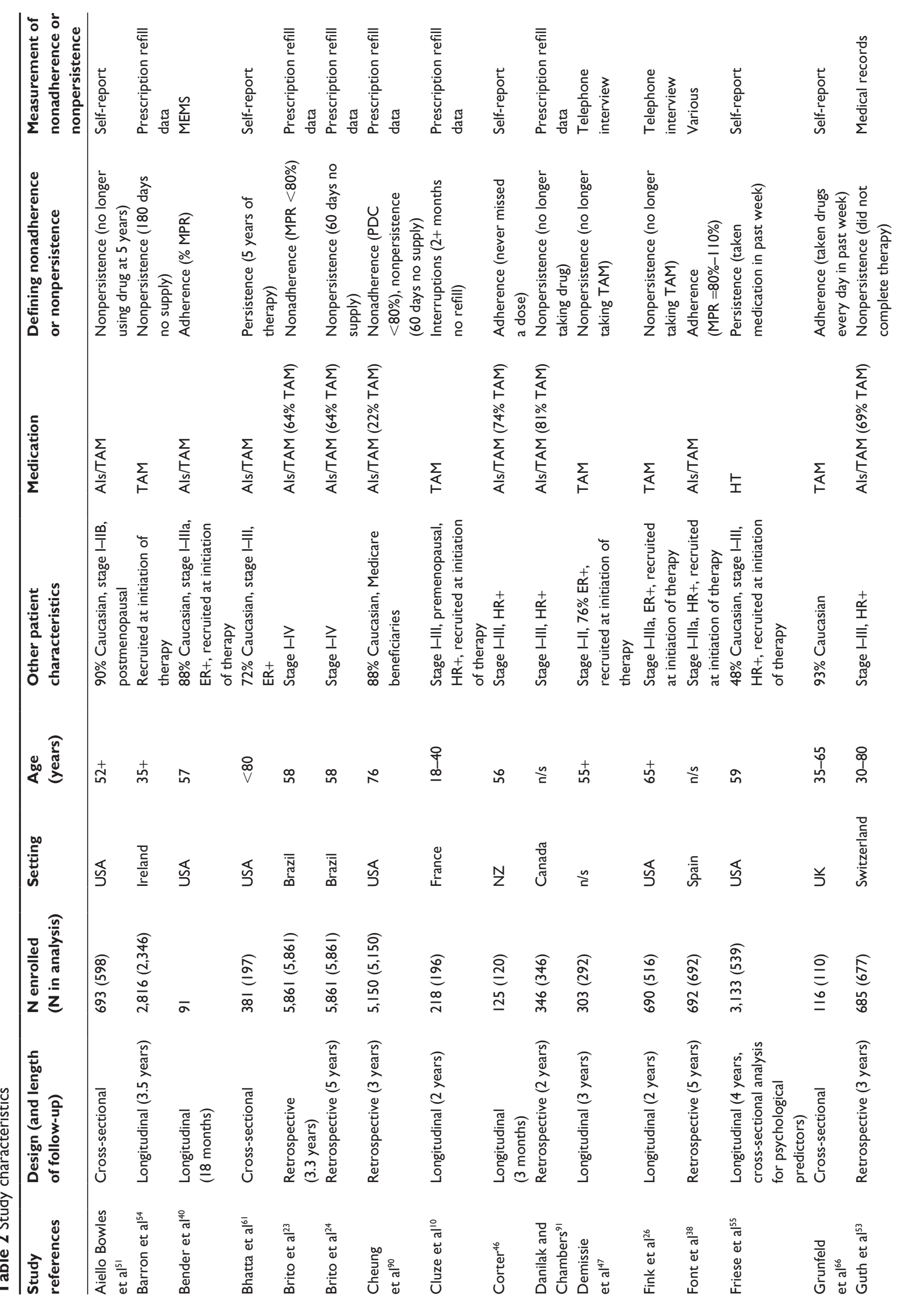




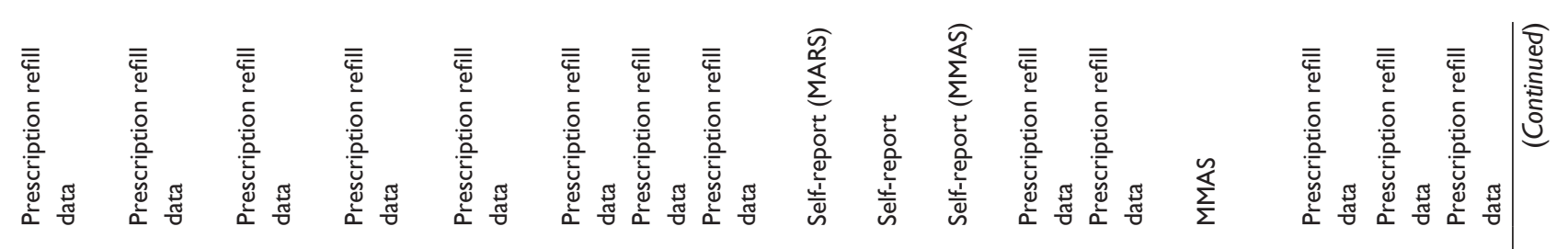

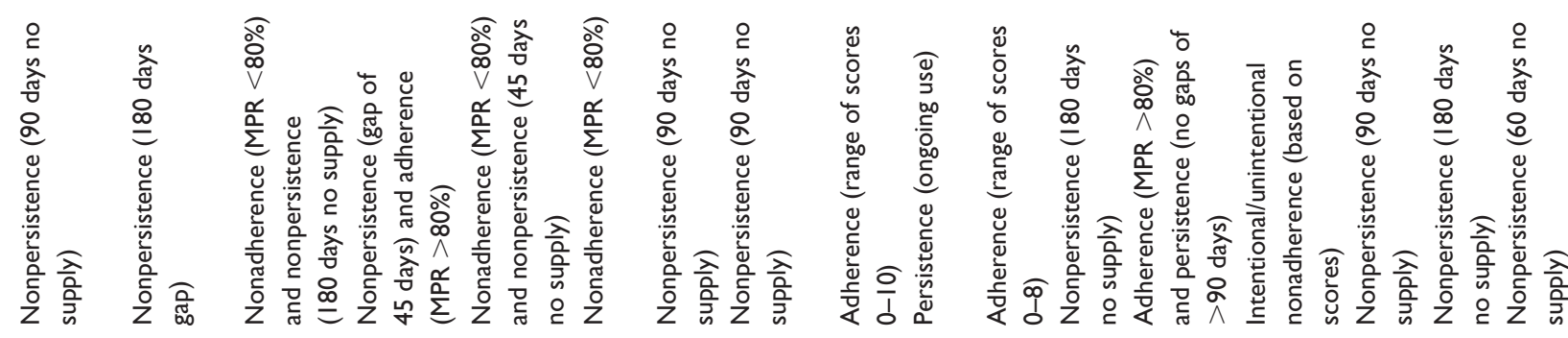
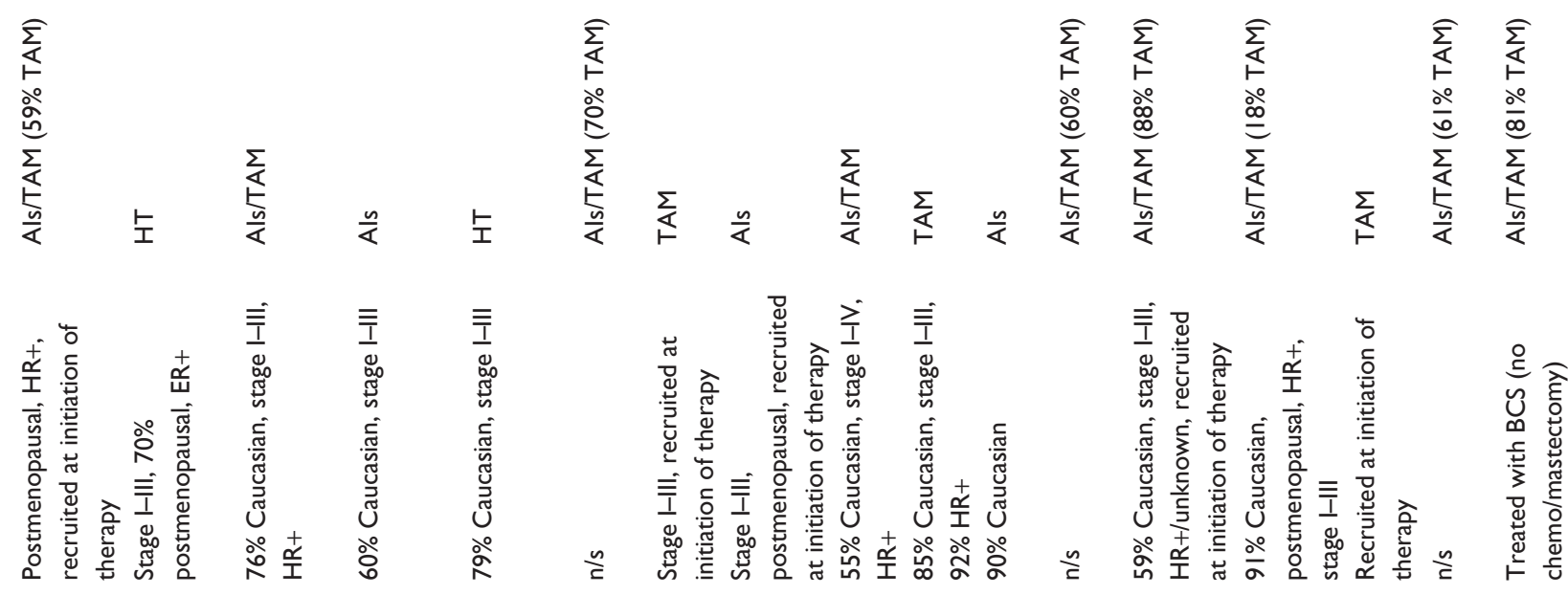

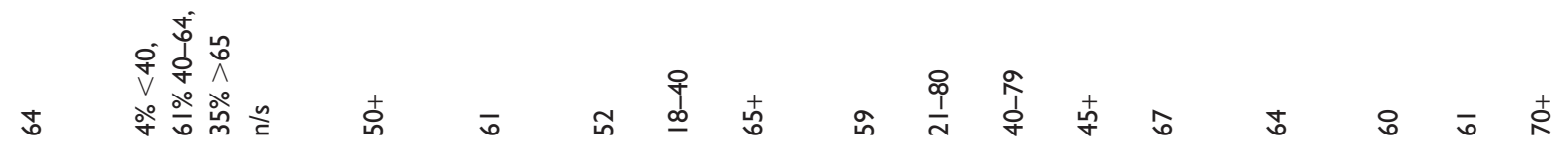

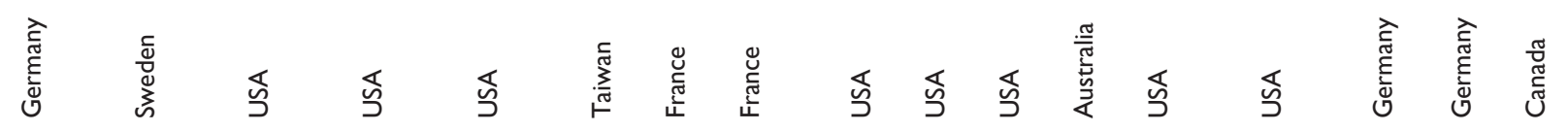

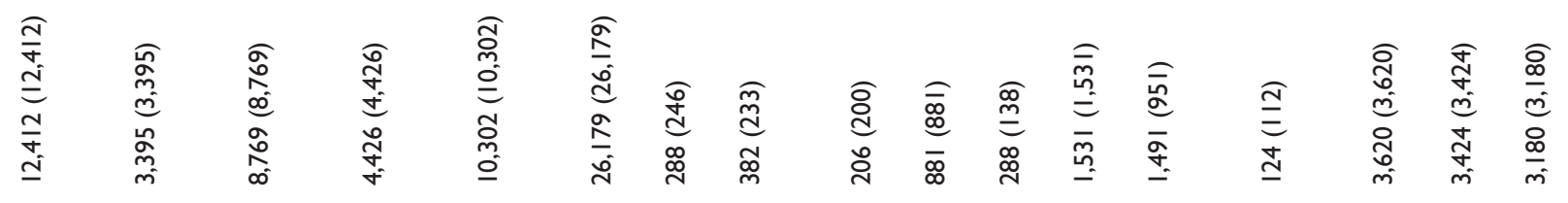

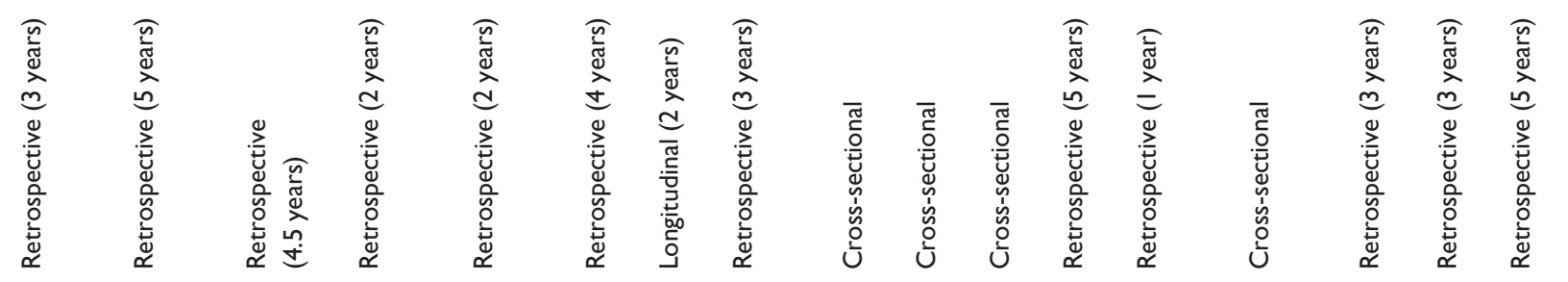

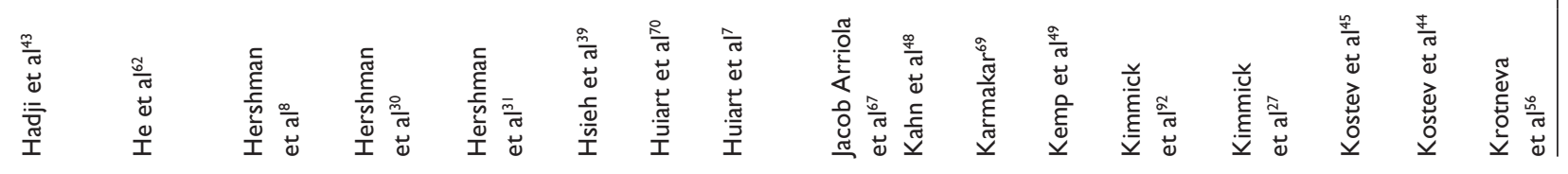




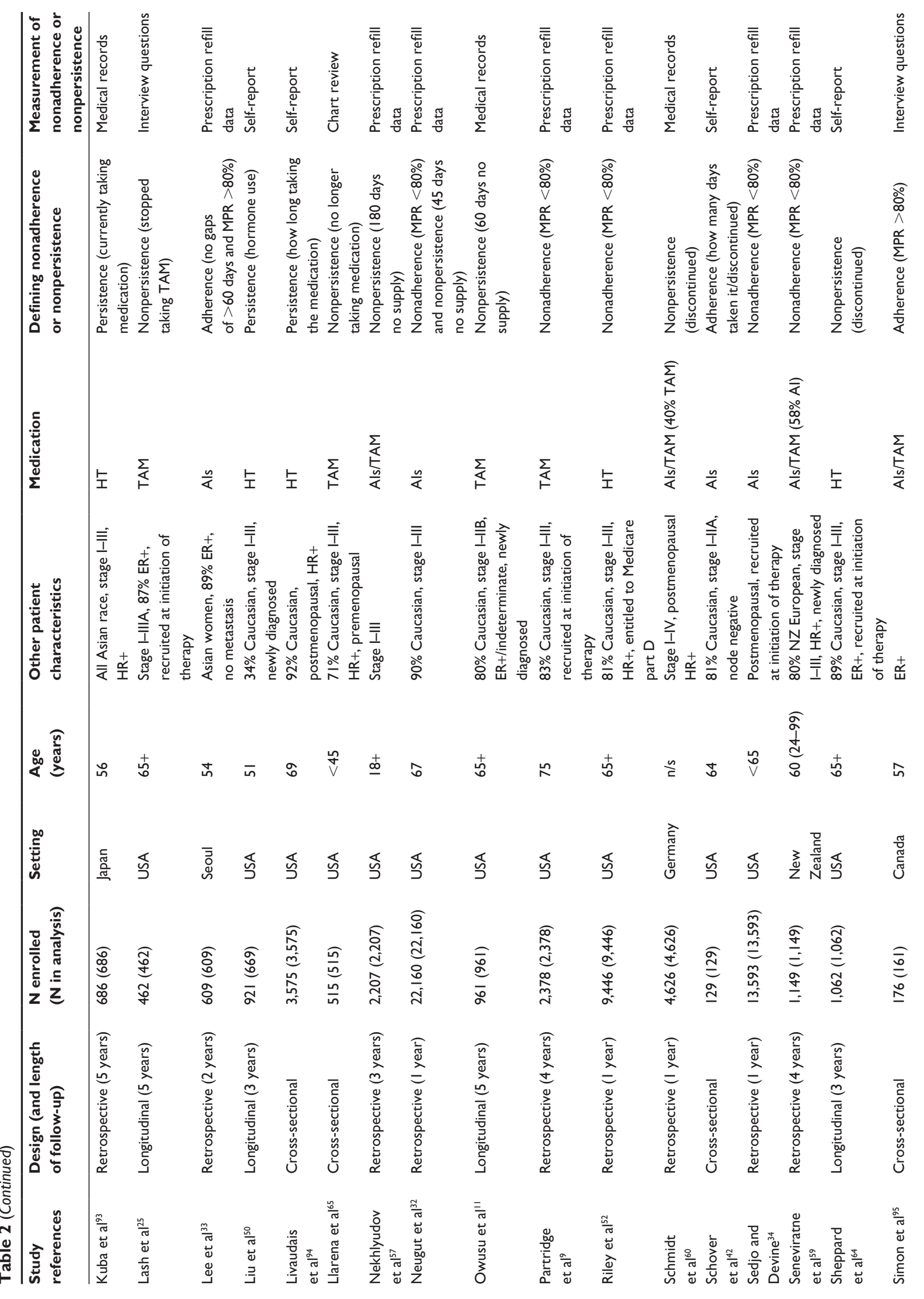




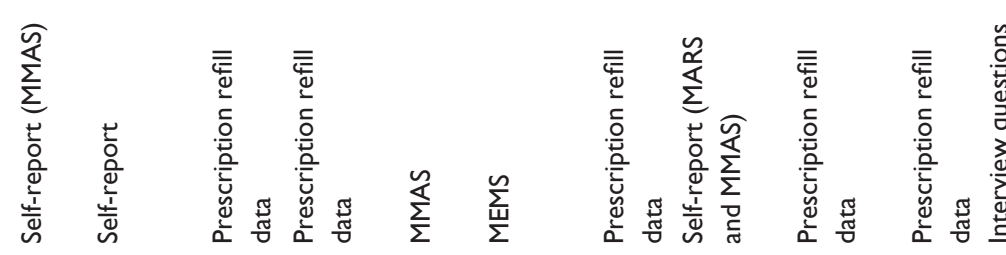

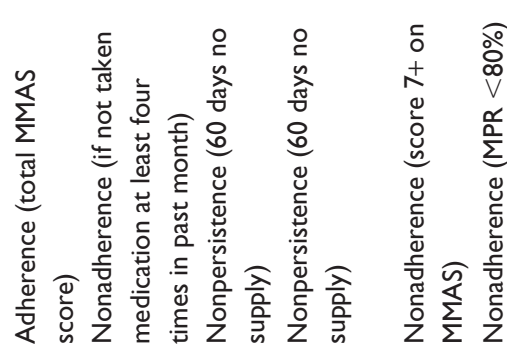

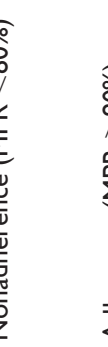

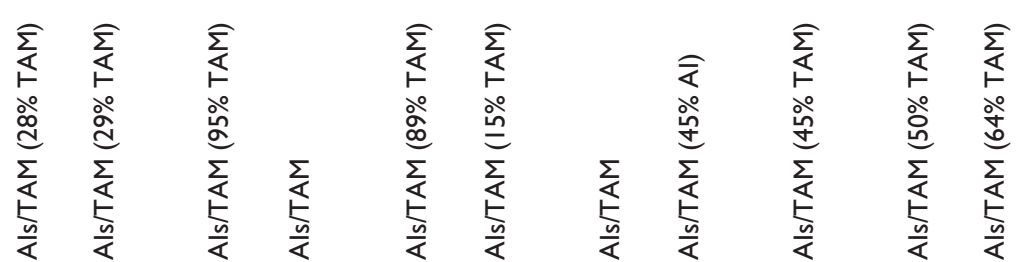

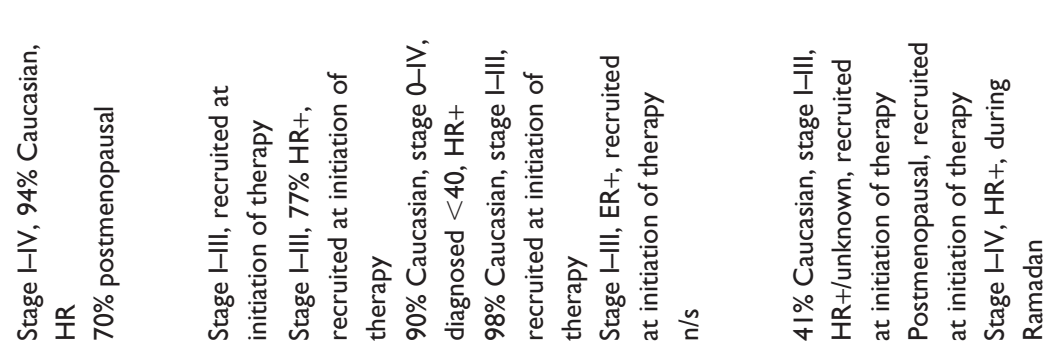

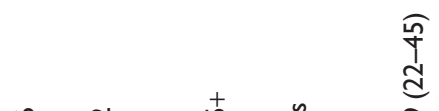

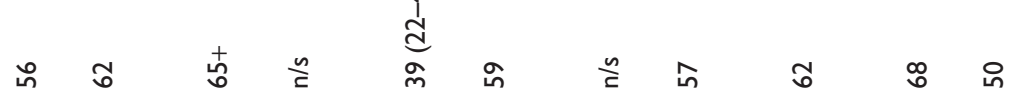

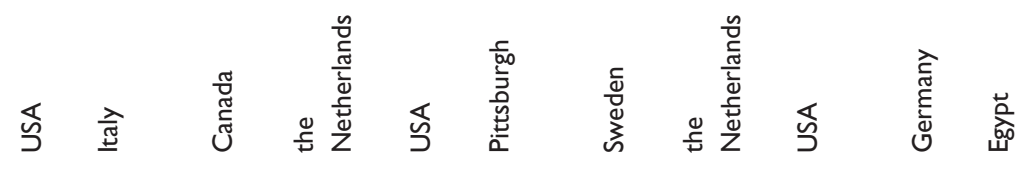

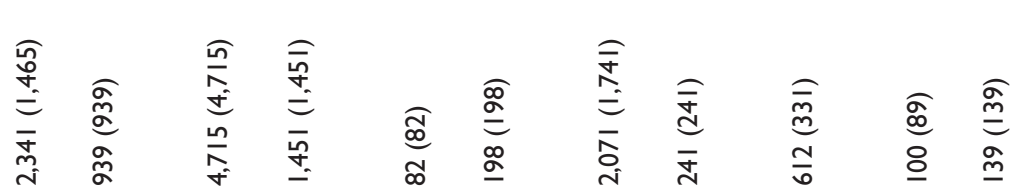

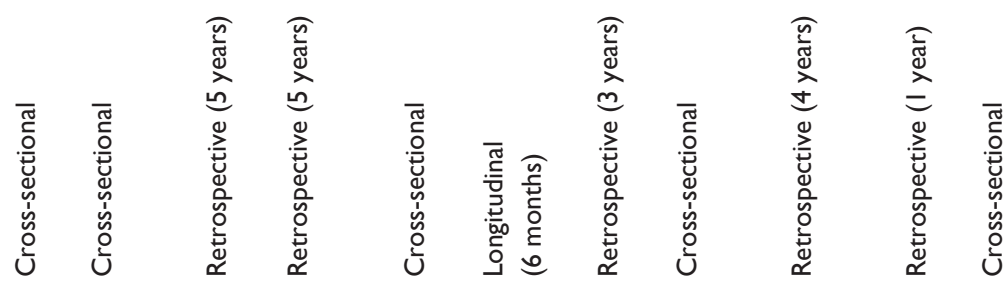

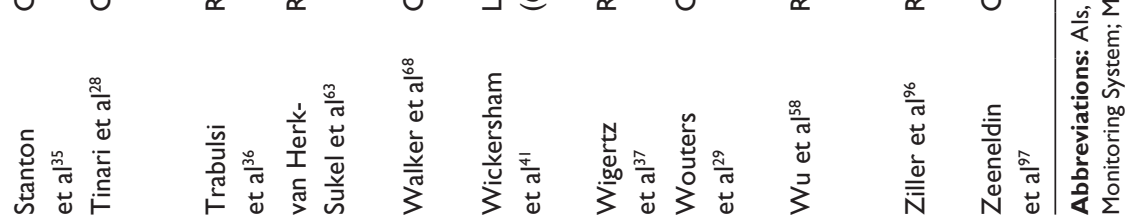


from the same sample..$^{23,24}$ One study was a follow-up analysis ${ }^{25}$ using the same sample as a previous study. ${ }^{26}$ All studies were included in the review. Studies were crosssectional $(n=16)$, retrospective $(n=32)$ and longitudinal $(n=13)$. Average follow-up for retrospective and longitudinal studies was 3.1 years $(\mathrm{SD}=1.4)$ and 2.7 years $(\mathrm{SD}=1.4)$, respectively. Twelve studies included patients prescribed tamoxifen, seven studies included patients prescribed AIs and 42 studies included patients on either therapy. Studies measured nonadherence ( $\mathrm{n}=25)$, discontinuation/ nonpersistence $(n=29)$, or both $(n=6)$. One study measured interruption, defined as a 60-day gap in treatment. Measurements included Medication Event Monitoring System (MEMS; $n=2$ ), medical records ( $\mathrm{n}=4$ ), prescription records $(n=27)$, self-report $(n=21)$ and a combination of measures $(n=7)$. Of the studies using self-report, only six studies used validated measures. Nonpersistence was defined as gaps in treatment of 45 days $(n=3), 60$ days $(n=8), 90$ days $(n=2)$ and 180 days $(n=6)$.

\section{Risk of bias in included studies}

The average quality score was $74 \%$, ranging from $33 \%$ to $100 \%$ (Table 3 ). The majority of studies were of moderate quality, but there were eleven low- $(\leq 50 \%)$ and 22 highquality ( $\geq 80 \%$ ) studies. Several studies using self-report data had a risk of selection bias, and some studies failed to use validated measures (Table 3). Only one-third of the studies

Table 3 Quality assessment

\begin{tabular}{|c|c|c|c|c|c|c|c|c|c|c|}
\hline References & A & B & C & D & $\mathbf{E}$ & $\mathbf{F}$ & G & $\mathbf{H}$ & I & Percentage \\
\hline Aiello Bowles et $\mathrm{a}^{51}$ & 1 & I & I & 1 & 0 & $\mathrm{I}$ & 1 & 0 & $\mathrm{n} / \mathrm{a}$ & 75 \\
\hline Barron et $\mathrm{al}^{54}$ & 0 & I & I & I & I & I & 1 & 0 & I & 78 \\
\hline Bender et $\mathrm{al}^{40}$ & I & 0 & I & I & 0 & I & 1 & 0 & 0 & 56 \\
\hline Bhatta et $\mathrm{a}^{61}$ & I & I & 0 & 0 & I & 0 & I & 0 & $\mathrm{n} / \mathrm{a}$ & 50 \\
\hline Brito et $\mathrm{a}^{23}$ & I & I & I & I & I & I & 1 & 0 & 0 & 78 \\
\hline Brito et $\mathrm{a}^{24}$ & I & I & I & I & I & I & 1 & 0 & I & 89 \\
\hline Cheung et $\mathrm{al}^{90}$ & I & I & I & I & I & I & 1 & 1 & I & 100 \\
\hline Cluze et $\mathrm{al}^{10}$ & $\mathrm{I}$ & 0 & I & 0 & I & I & 1 & 1 & I & 78 \\
\hline Corter ${ }^{46}$ & $\mathrm{I}$ & I & 0 & I & $\mathrm{I}$ & I & I & 0 & I & 78 \\
\hline Danilak and & I & 1 & I & I & I & I & I & 0 & I & 89 \\
\hline \multicolumn{11}{|l|}{ Chambers $^{91}$} \\
\hline Demissie et $\mathrm{al}^{47}$ & $\mathrm{I}$ & I & 0 & I & $\mathrm{I}$ & I & 1 & I & 0 & 78 \\
\hline Fink et $\mathrm{al}^{26}$ & I & 0 & I & 0 & I & I & 1 & 0 & I & 67 \\
\hline Font et $\mathrm{al}^{38}$ & I & I & I & I & $\mathrm{I}$ & I & I & I & 0 & 89 \\
\hline Friese et $\mathrm{al}^{55}$ & I & I & 0 & I & $\mathrm{I}$ & I & 1 & I & I & 89 \\
\hline Grunfeld et al ${ }^{66}$ & 0 & 0 & I & I & 0 & 0 & 1 & 0 & $\mathrm{n} / \mathrm{a}$ & 38 \\
\hline Guth et $\mathrm{a}^{53}$ & I & I & 0 & I & I & I & 1 & I & I & 89 \\
\hline Hadji et $\mathrm{a}^{43}$ & I & I & I & I & I & I & I & 0 & 0 & 78 \\
\hline He et $a^{62}$ & I & I & I & I & I & I & 1 & I & I & 100 \\
\hline Hershman et $\mathrm{al}^{8}$ & I & I & I & I & I & I & I & I & I & 100 \\
\hline
\end{tabular}

(Continued)
Table 3 (Continued)

\begin{tabular}{|c|c|c|c|c|c|c|c|c|c|c|}
\hline References & $\mathbf{A}$ & B & C & D & $\mathbf{E}$ & $\mathbf{F}$ & G & $\mathbf{H}$ & $\mathbf{I}$ & Percentage \\
\hline Hershman et $\mathrm{a}^{30}$ & 0 & 1 & 1 & I & 1 & 1 & 1 & 0 & 0 & 67 \\
\hline Hershman et $\mathrm{al}^{31}$ & I & I & I & I & I & 1 & 1 & 0 & I & 89 \\
\hline Hsieh et $\mathrm{al}^{39}$ & I & I & I & I & I & 1 & I & 0 & 1 & 89 \\
\hline Huiart et $\mathrm{a}^{70}$ & I & I & I & I & I & 1 & 1 & I & 1 & 100 \\
\hline Huiart et $\mathrm{al}^{7}$ & I & I & I & I & I & 1 & I & I & 0 & 89 \\
\hline Jacob Arriola et al ${ }^{67}$ & I & 0 & I & I & I & I & 1 & I & 0 & 78 \\
\hline Kahn et al ${ }^{48}$ & I & 0 & 0 & 0 & I & I & 1 & I & $\mathrm{n} / \mathrm{a}$ & 63 \\
\hline Karmakar ${ }^{69}$ & $\mathrm{I}$ & 0 & I & I & 0 & 1 & I & I & $\mathrm{n} / \mathrm{a}$ & 75 \\
\hline Kemp et al ${ }^{49}$ & I & I & I & I & I & 1 & I & I & 1 & 100 \\
\hline Kimmick et $\mathrm{al}^{92}$ & I & I & 1 & I & I & 1 & 1 & 0 & 1 & 89 \\
\hline Kimmick et $\mathrm{al}^{27}$ & I & I & I & I & I & 1 & 1 & 0 & I & 89 \\
\hline Kostev et $\mathrm{al}^{45}$ & I & I & 0 & I & I & 1 & 1 & 0 & 0 & 67 \\
\hline Kostev et al ${ }^{44}$ & 0 & I & 0 & I & I & I & 1 & 0 & 0 & 56 \\
\hline Krotneva et $\mathrm{al}^{56}$ & 0 & I & I & I & I & 1 & I & 0 & 0 & 66 \\
\hline Kuba et al ${ }^{93}$ & I & I & 0 & I & 0 & 0 & I & 0 & 0 & 44 \\
\hline Lash et $\mathrm{al}^{25}$ & I & 0 & 0 & 0 & I & 1 & 1 & 0 & 0 & 44 \\
\hline Lee et $\mathrm{al}^{33}$ & I & I & I & $\mathrm{I}$ & I & 1 & 1 & I & I & 100 \\
\hline Liu et $\mathrm{a}^{50}$ & I & 0 & 0 & I & I & 0 & 1 & 0 & 0 & 44 \\
\hline Livaudais et $\mathrm{al}^{94}$ & I & I & 0 & I & I & I & I & 0 & $\mathrm{n} / \mathrm{a}$ & 75 \\
\hline Llarena et al ${ }^{65}$ & I & I & 1 & $\mathrm{I}$ & I & 1 & 1 & I & $\mathrm{n} / \mathrm{a}$ & 100 \\
\hline Nekhlyudov et al ${ }^{57}$ & I & I & 1 & I & I & 1 & I & 0 & 0 & 78 \\
\hline Neugut et $\mathrm{a}^{32}$ & I & I & 1 & $\mathrm{I}$ & I & I & 1 & I & I & 100 \\
\hline Owusu et al" & I & I & 0 & I & I & 1 & 1 & I & 0 & 78 \\
\hline Partridge et $\mathrm{al}^{9}$ & I & I & I & I & I & 1 & 1 & I & I & 100 \\
\hline Riley et $\mathrm{a}^{52}$ & I & I & I & I & I & 1 & I & 0 & 0 & 78 \\
\hline Schmidt et $\mathrm{al}^{60}$ & I & I & 0 & I & I & I & 1 & 0 & 0 & 67 \\
\hline Schover et $\mathrm{al}^{42}$ & 0 & I & 0 & I & 0 & 1 & 0 & 0 & $\mathrm{n} / \mathrm{a}$ & 38 \\
\hline Sedjo and Devine ${ }^{34}$ & I & 1 & I & I & I & 1 & 1 & 0 & 0 & 78 \\
\hline Seneviratne et $\mathrm{a}^{59}$ & I & I & 1 & $\mathrm{I}$ & I & 1 & 1 & 0 & 0 & 78 \\
\hline Sheppard et al ${ }^{64}$ & I & I & 0 & 1 & I & 1 & 1 & 1 & 0 & 78 \\
\hline Simon et a $\left.\right|^{95}$ & I & 0 & I & I & I & 1 & 1 & 0 & $\mathrm{n} / \mathrm{a}$ & 75 \\
\hline Stanton et $\mathrm{al}^{35}$ & I & 0 & I & $\mathrm{I}$ & I & I & 1 & 0 & $\mathrm{n} / \mathrm{a}$ & 75 \\
\hline Tinari et $\mathrm{al}^{28}$ & 0 & I & 0 & 0 & I & 1 & I & 0 & $\mathrm{n} / \mathrm{a}$ & 50 \\
\hline Trabulsi et $\mathrm{al}^{36}$ & I & I & I & I & I & I & 1 & I & 0 & 89 \\
\hline van Herk-Sukel & I & I & I & $\mathrm{I}$ & I & 1 & I & I & I & 100 \\
\hline
\end{tabular}

et $\mathrm{al}^{63}$

$\begin{array}{lllllllllll}\text { Walker et al }^{68} & \text { I } & 0 & \text { I } & 0 & 0 & \text { I } & 0 & \text { I } & \text { n/a } & 50\end{array}$

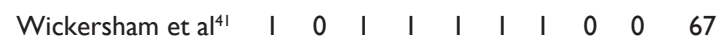

$\begin{array}{lllllllllll}\text { Wigertz et a }{ }^{37} & \mathrm{I} & \mathrm{I} & \mathrm{l} & \mathrm{I} & \mathrm{I} & \mathrm{I} & \mathrm{I} & 0 & \mathrm{I} & 89\end{array}$

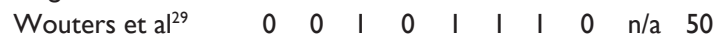

$\begin{array}{lllllllllll}\text { Wu et a }\left.\right|^{58} & \mathrm{I} & \mathrm{I} & \mathrm{I} & \mathrm{I} & \mathrm{I} & \mathrm{I} & \mathrm{I} & 0 & 0 & 78\end{array}$

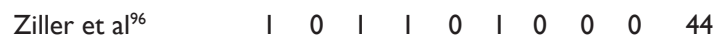

$\begin{array}{lllllllllll}\text { Zeeneldin et al }^{97} & \text { I } & 0 & 0 & \text { I } & 0 & 0 & \text { I } & 0 & \text { n/a } & 38\end{array}$

Notes: A: Are the main features of the study population described? B: Is participation $>80 \%$ or $60 \%-80 \%$ with no difference between responders and nonresponders? C: Is adherence measured appropriately and clearly described? D: Are other outcome variables measured appropriately? E: Did the analysis control for confounding? F: Are quantitative measures of association presented? G: Was the number of cases in the multivariate analysis at least ten times the number of independent variables in the final model? $\mathrm{H}$ : Was physician recommended nonadherence removed? I: Were losses of patients to follow-up taken into account? Abbreviation: $\mathrm{n} / \mathrm{a}$, not applicable.

removed women from analysis who had had a recurrence or died and, therefore, were no longer prescribed HT.

\section{Summary of results}

The percentage of women categorized as adherent ranged from $47 \%$ to $97 \%$ (mean $=74 \%, \mathrm{SD}=13 \%$ ) and fell from an 
average of $79 \%$ in the first year of treatment to $56 \%$ in the fourth or fifth year. Studies using MEMS found the highest adherence rate $(93 \%)$, followed by self-report (82\%) and prescription refill rates $(75 \%)$. Unintentional nonadherence (eg, forgetting) was specifically measured in three studies and was found to be more common than intentional nonadherence $($ mean $=31 \%$ vs $15 \%) .{ }^{27-29}$ Discontinuation ranged from $9 \%$ to $63 \%($ mean $=30 \%, \mathrm{SD}=12 \%)$. Discontinuation rose from an average of $21 \%$ in the first year to $48 \%$ in the fifth year. Rates of discontinuation were similar across different measurements (prescription refill, self-report and medical records). In some studies, nonpersistence and nonadherence are clearly separated, making it possible to combine the nonpersistence rates $(23 \%-32 \%)$ with the nonadherence rates $(9 \%-28 \%)$ to calculate the total proportion of the original sample who are not taking their medication as prescribed. In these studies, this amounts to $33 \%-50 \%$ across $2-4$ years of treatment, which highlights the extent of the problem of nonadherence in this population. ${ }^{8,30-32}$ However, it is not possible to calculate this from other studies due to measurement and classification issues. For example, many studies provide nonadherence figures (using self-report, MEMS and prescription refill) without being explicit as to whether nonpersistent women were removed from analysis or were classed as nonadherent. Others stated that those who discontinued were removed from analysis but have not provided discontinuation rates. Finally, some authors have classed participants who discontinued treatment as nonadherent and some have allowed participants to be both nonpersistent and nonadherent. Therefore, accurate estimates of nonadherence and nonpersistence rates are currently lacking.

\section{Correlates of adherence and persistence}

A large number of variables showed no significant relationship with HT adherence or persistence (Table 4). The remaining factors are discussed later. For the purpose of synthesizing results, variables have been classed as having a positive effect, a negative effect, or no effect on adherence/ persistence. A positive/negative effect indicates a statistically significant relationship $(P<0.05)$ between adherence or persistence and the predictor variable.

\section{Clinical factors}

\section{Adherence}

The majority of clinical factors showed no consistent associations with adherence or showed mixed results (eg, tumor size, previous chemotherapy and lymph node status). Switching between HTs was associated with decreased adherence in seven studies ${ }^{23,28,33-37}$ and increased adherence in three studies. $^{8,38,39}$ The majority of articles did not specify the direction of switching between medications.

Regarding overall side effects, two studies showed a negative relationship with adherence ${ }^{27,29}$ and three studies found no significant effects (Table 5). Hot flushes/vasomotor symptoms, incontinence, gastrointestinal symptoms and sex-related symptoms were not associated with adherence, whereas weight concerns were associated with decreased odds of adherence. ${ }^{40,41}$ Cognitive, gynecological, musculoskeletal and sleep/fatigue-related symptoms were associated with lower odds of adherence in some studies, but the effects were not consistently found. ${ }^{40-42}$

\section{Persistence}

Similar to adherence, the majority of clinical factors were not reliably associated with persistence for the prescribed treatment duration. Three studies found that a codiagnosis of osteoporosis or diabetes was related to increased persistence. ${ }^{43-45}$ However, mixed results were found for the effects of comorbidities in general, with the majority of studies finding no significant associations.

Five studies found that experiencing any/severe side effects was associated with decreased odds of persistence, ${ }^{25,35,46-48}$ but three studies found no significant effects. Women who experienced menopause-related side effects were up to three times less likely to persist ${ }^{10,49,50}$ in three studies but more likely to persist with treatment in two studies. ${ }^{48,51}$ Hair thinning was associated with increased odds of persistence, but headaches and loss of appetite showed the opposite effect. ${ }^{51}$ Gynecological symptoms were associated with increased odds of persistence in one study, ${ }^{51}$ but another two studies found no significant effects.

\section{Health care factors}

\section{Adherence}

Consultations with an oncologist or mastologist increased odds of adherence in two studies compared to women without these consultations. ${ }^{9,23}$ Experiencing more hospitalizations was associated with lower odds of adherence. ${ }^{9,23,34,36}$ Higher monthly prescription costs were associated with decreased odds of adherence in four studies, ${ }^{30,32,34,52}$ but two studies found no significant effects.

\section{Persistence}

Five studies showed that odds of persistence increased by $21 \%-66 \%$ if treatment was received by an oncologist or a gynecologist as opposed to a general practitioner, ${ }^{32,43-45,53}$ 


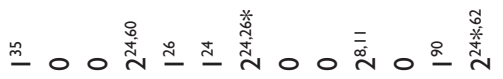

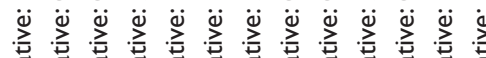

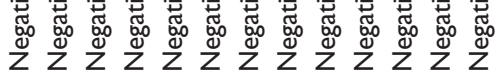

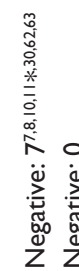

\section{先}

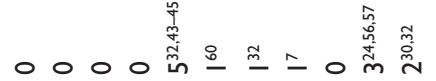

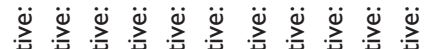

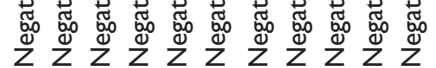

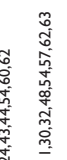

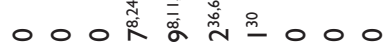

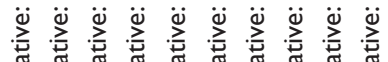

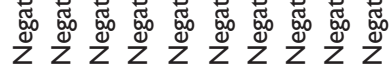

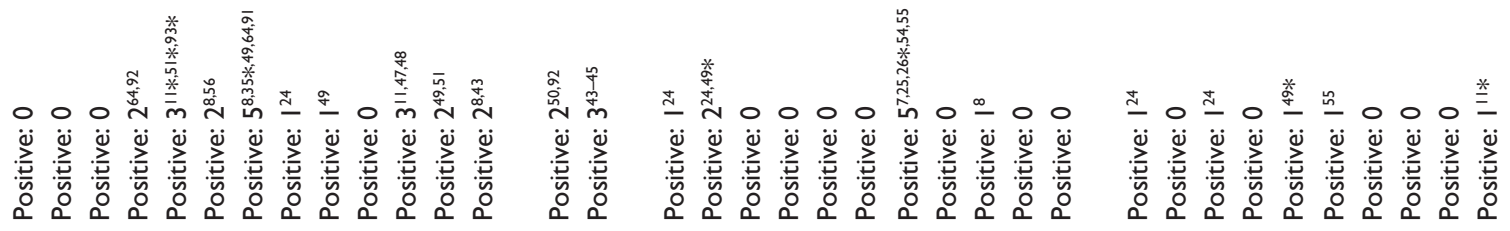

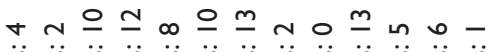
ن⿺辶寸

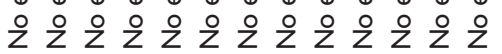

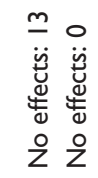

om- O N O moo-m

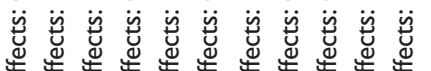

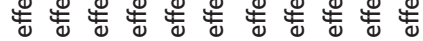

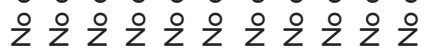

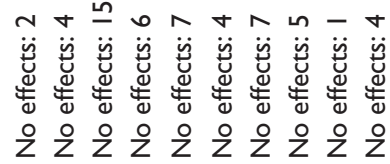

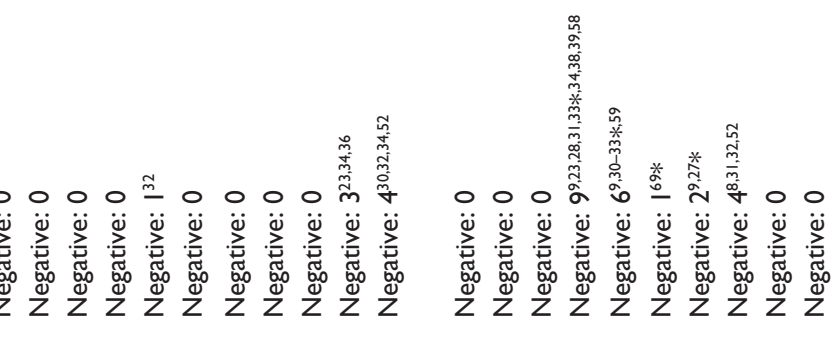

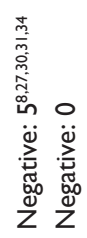

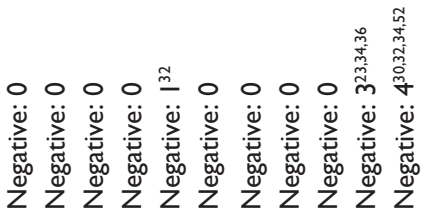
ż z z z z z z z z z z

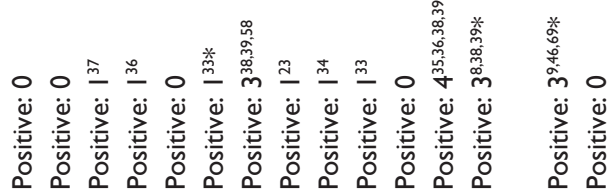

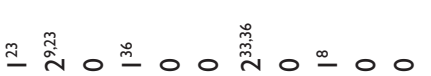

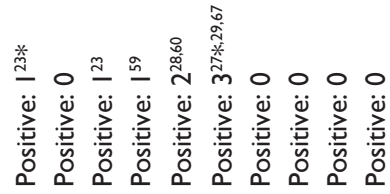

$m--\simeq m=a m$ 으 $m$ 응

$a$

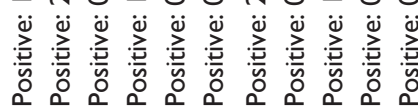

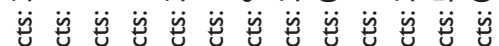

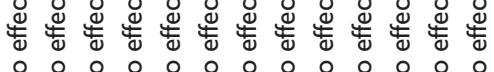

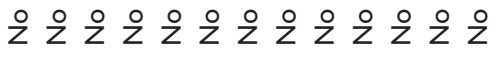

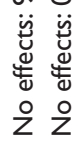

$0000-0000-1$

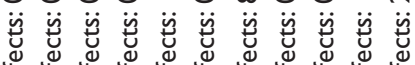

$\sim m \underline{m} m$ Ln a $\infty m$ o n

نु

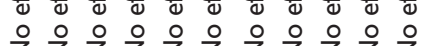

z년

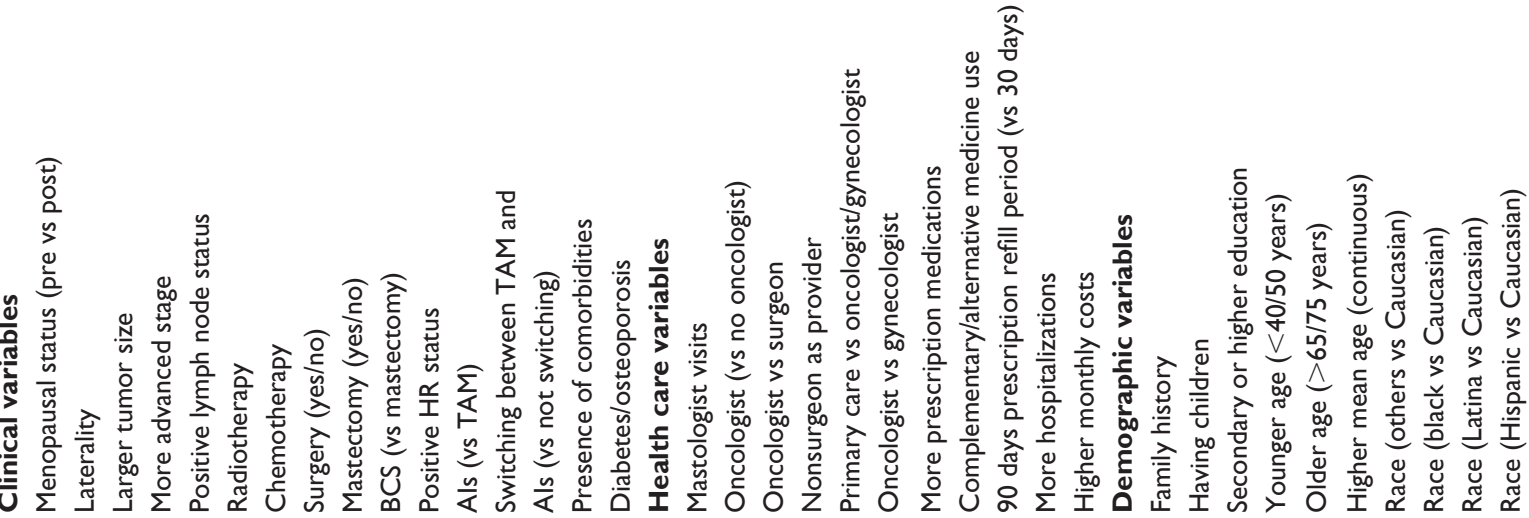




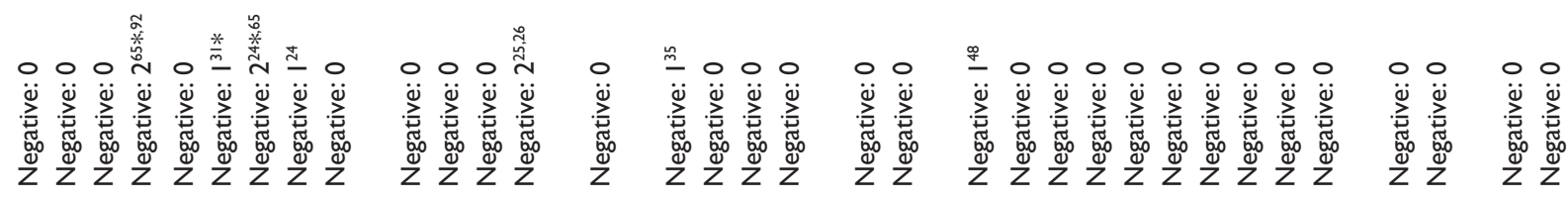

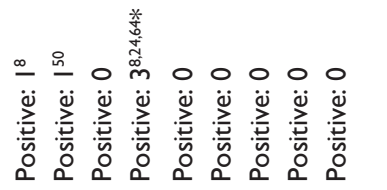

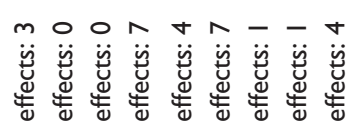

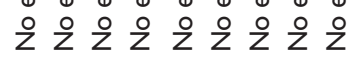

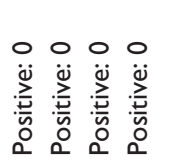

일.

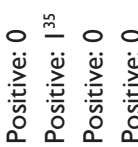

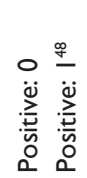

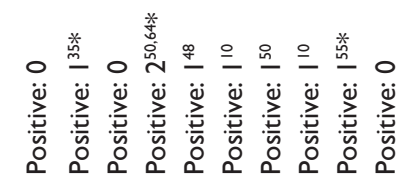

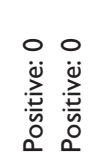

总

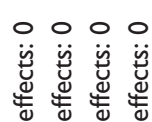
z 은 운

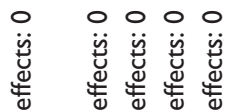

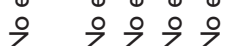

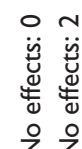

o o o m o o o o - 0

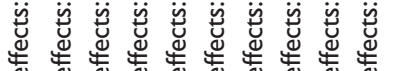

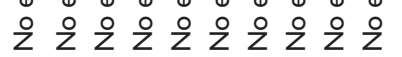

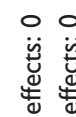
z z z

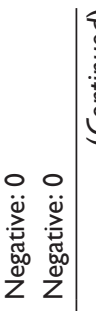




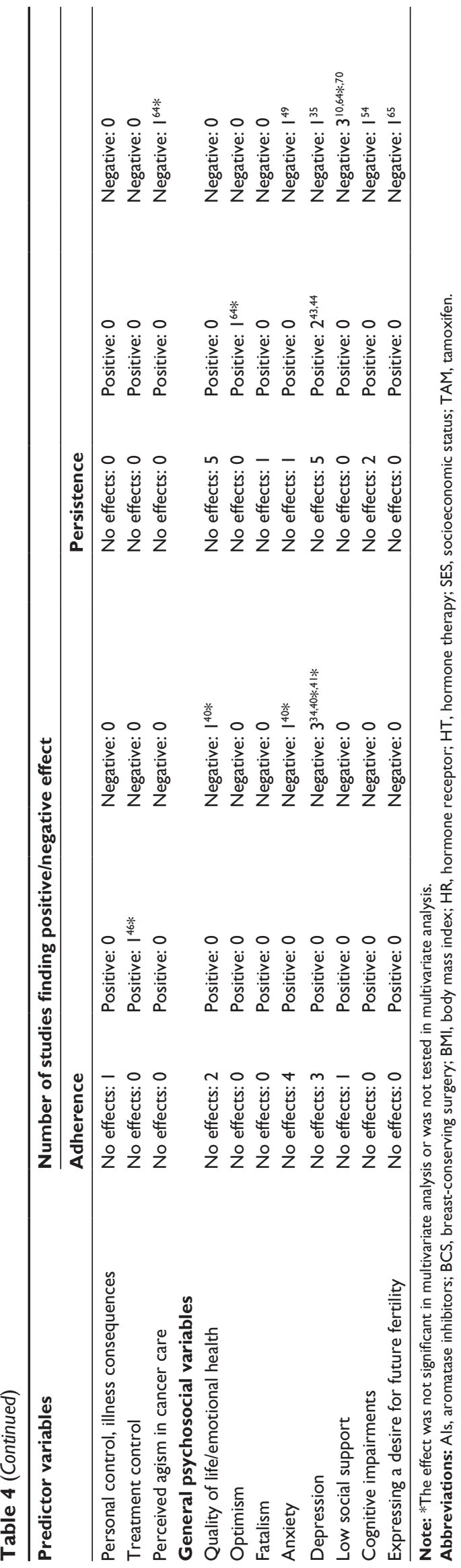

while two studies found no significant effect. Five studies found that being prescribed more medications per month was associated with increased odds of persistence, ; $^{7,25,26,54,55}$ however, an additional study showed the opposite effect ${ }^{32}$ and three studies found no significant effects. Furthermore, two of the studies showing a positive effect used the same sample at different time points. ${ }^{25,26}$ Three studies found that women who were hospitalized more were less likely to persist with treatment, ${ }^{24,56,57}$ but one study found no significant effects. Women who used complementary or alternative therapies had lower odds of persistence. ${ }^{7}$

\section{Demographic factors}

\section{Adherence}

Nine studies showed lower odds of adherence for women under the age of $40 / 50$ years, ${ }^{9,23,28,31,33,34,38,39,58}$ one study found the opposite, ${ }^{59}$ and three studies showed no significant effects. Six studies found that older women ( $>65 / 75$ years) were less likely to be adherent. ${ }^{9,30-33,59}$ However, two studies found the opposite effect ${ }^{28,60}$ and six studies found no effects. Four studies found that being black was associated with lower odds of adherence than being white, ${ }^{8,31,32,52}$ but a further three studies found no significant effects for this relationship. ${ }^{30,58,61}$

\section{Persistence}

There was a trend suggesting that younger ( $<45 / 50$ years) women had lower odds of persistence, ${ }^{8,24,43,45,54,60,62}$ but this was not always supported. Nine studies showed that older women were less likely to persist with treatment, $8,11,30,32,48,54,57,62,63$ but seven studies found no significant association and one study found the opposite effect. ${ }^{49}$

\section{Psychosocial factors}

The following variables showed significant effects on adherence but were only tested in one study: illness coherence ${ }^{46}$ and self-efficacy regarding learning about medication ${ }^{29}$ (positive effect on adherence) and practical problems associated with medication taking ${ }^{29}$ (negative effect on adherence). Optimism showed a positive effect on persistence, ${ }^{64}$ and expressing a future desire for fertility had a negative effect on persistence. ${ }^{65}$

\section{Adherence}

There was some evidence suggesting that medication beliefs were related to adherence. Three studies showed that "necessity beliefs", defined as judgments of personal need for the treatment, ${ }^{12}$ were significantly related to increased adherence. ${ }^{35,66,67}$ The adherence estimator measures 
Table 5 Relationship between side effects and HT adherence/ persistence

\begin{tabular}{|c|c|c|}
\hline \multirow[t]{2}{*}{ Variable } & \multicolumn{2}{|c|}{$\begin{array}{l}\text { Number of studies showing } \\
\text { positive/negative effect }\end{array}$} \\
\hline & Adherence & Persistence \\
\hline Any side effects & $\begin{array}{l}2 \times \text { negative }^{27 *, 29} \\
3 \times \text { no effects }\end{array}$ & $\begin{array}{l}3 \times \text { negative }{ }^{35 * 46 *, 47} \\
2 \times \text { no effects }\end{array}$ \\
\hline Severe side effects & 0 & $\begin{array}{l}2 \times \text { negative } 25,48 \\
1 \times \text { no effects }\end{array}$ \\
\hline $\begin{array}{l}\text { Overall hormone/ } \\
\text { menopause related }\end{array}$ & 0 & $\begin{array}{l}1 \times \text { positive }^{51 *} \\
2 \times \text { negative }^{10,50}\end{array}$ \\
\hline $\begin{array}{l}\text { Hot flushes/vasomotor } \\
\text { symptoms/sweating }\end{array}$ & $5 \times$ no effects & $\begin{array}{l}\mathrm{I} \times \text { positive }^{48} \\
\mathrm{I} \times \text { negative }^{49} \\
\mathrm{I} \times \text { no effects }\end{array}$ \\
\hline Overall sleep/fatigue related & $2 \times$ no effects & $2 \times$ no effects \\
\hline Gynecological symptoms & $\begin{array}{l}\text { I× positive }{ }^{42 *} \\
2 \times \text { negative }^{40 *, 41 *} \\
3 \times \text { no effects }\end{array}$ & $\begin{array}{l}1 \times \text { positive }^{51 *} \\
2 \times \text { no effects }\end{array}$ \\
\hline Sex-related symptoms & $4 \times$ no effects & $2 \times$ no effects \\
\hline $\begin{array}{l}\text { Joint aches and pains/ } \\
\text { osteoporosis }\end{array}$ & $\begin{array}{l}2 \times \text { negative }{ }^{40 *}, 41 * \\
2 \times \text { no effects }\end{array}$ & $2 \times$ no effects \\
\hline Weight concerns & $\begin{array}{l}2 \times \text { negative }^{40 *, 41} \\
\mid \times \text { no effects }\end{array}$ & I $\times$ no effects \\
\hline Incontinence/bladder control & $3 \times$ no effects & I $\times$ no effects \\
\hline Hair thinning/loss & 0 & $\mathrm{I} \times$ positive $^{5 \mathrm{I} *}$ \\
\hline Headaches & 0 & $\mid \times$ negative $^{5 \mid *}$ \\
\hline Loss of appetite & 0 & $\mid \times$ negative $^{5 \mid *}$ \\
\hline Gastrointestinal symptoms & $2 \times$ no effects & 0 \\
\hline Cognitive symptoms & $\begin{array}{l}2 \times \text { negative }{ }^{40 *, 41 *} \\
1 \times \text { no effects }\end{array}$ & 0 \\
\hline
\end{tabular}

Notes: Individual symptoms that were only tested in one study and were not significant are not listed (shortness of breath, eyesight changes, breast sensitivity, fractures/broken bones and retaining water). *The effect was not significant in multivariate analysis or was not tested in multivariate analysis.

Abbreviation: $\mathrm{HT}$, hormone therapy.

perceived need for medication, concerns and affordability and categorizes people as low, medium and high risk for nonadherence. Women who were high risk were more likely to report being nonadherent. ${ }^{42}$ Negative and positive emotions regarding therapy were related to decreased and increased adherence, respectively, ${ }^{35,68}$ and perceived importance of therapy was related to increased adherence. ${ }^{61}$ Karmakar $^{69}$ found that coping appraisal, defined as the effectiveness of taking HT and self-efficacy in ability to take HT, minus the costs of taking HT, was associated with increased odds of adherence. Four studies found no effects of necessity beliefs on adherence. ${ }^{27,40,46,68}$ These four studies had small sample sizes and may have lacked power to find a significant effect. However, where effect sizes were given, they were relatively small. Three studies found a positive relationship between perceived self-efficacy for medication taking and adherence. ${ }^{27,29,69}$

Variables relating to patient-physician relationship tended to be associated with adherence. Patient-physician relationship quality, ${ }^{35}$ value of doctor's opinion, ${ }^{61}$ frequency of physician communication, ${ }^{67}$ and self-efficacy in patientphysician communication ${ }^{27}$ were positively associated with adherence. However, several of these were only tested in univariate analysis and in single studies.

\section{Persistence}

Having a neutral or negative decisional balance score, ie, believing that the benefits of the treatment do not outweigh the harms, was associated with three times lower odds of persistence within the first 2 years of therapy. ${ }^{26} \mathrm{~A} 5$-year follow-up study supported this relationship but with a smaller effect size. ${ }^{25}$ Positive and negative emotions regarding HT were associated with increased/decreased odds of adherence. ${ }^{35}$

Results for patient-physician relationship were mixed. Two studies found that perceptions of better physician communication were associated with increased odds of persistence, ${ }^{50,64}$ but three studies found no significant effects. However, one of these effects was nearing significance. ${ }^{25}$ Being involved in decisions and discussing $\mathrm{HT}$ with a doctor were found to have no significant effects on persistence in two studies and a positive effect in one study. ${ }^{48}$ However, being able to ask questions and understanding information, ${ }^{10}$ self-efficacy in patient-physician interaction, ${ }^{50}$ and receiving the right amount of support ${ }^{48}$ were significantly related to increased persistence.

Two studies showed that no longer fearing cancer recurrence was associated with an increased risk of treatment interruption, ${ }^{10,55}$ but this did not remain significant in multivariate analysis..$^{55}$ Three studies found that women reporting low levels of social support were less likely to persist with treatment. ${ }^{10,64,70}$

\section{Discussion}

This article reviewed the evidence for clinical, demographic and psychosocial predictors of HT adherence and persistence to present a holistic view of the evidence base. Empirical interest in this area is growing, and this review builds upon previous reviews by incorporating 27 new studies. One previous review concluded that social support, patient-centered interactions, anxiety and beliefs were related to nonadherence/nonpersistence. ${ }^{18}$ While this current review supports some of these findings, new research has questioned whether anxiety is related to nonadherence. Cahir et a $\mathrm{a}^{17}$ found that side effects and follow-up care with a GP (vs oncologist) was negatively associated with persistence and the number of medications was positively associated with persistence. This review supported the previous findings that receiving 
care from an oncologist was associated with increased persistence but found mixed results for the number of medications and side effects. This review also highlighted new factors, such as younger age and hospitalizations, and moved beyond these findings to identify modifiable factors, such as selfefficacy for medication taking.

Researchers and clinicians often assume that side effects, especially menopausal symptoms, trigger nonadherence. ${ }^{71,72}$ Although some studies found a relationship between side effects and adherence/persistence, the relationship was not always supported. ${ }^{73}$ However, studies investigating the effects of hot flushes were low to moderate quality, so further high-quality research is needed. Several studies found that nonadherent or nonpersistent women reported fewer side effects, possibly as a result of not taking the medication. Future research should therefore measure adherence and side effects at several time points to see how the relationship changes across time. Qualitative research has shown that some women would not discontinue HT regardless of its side effects (Moon Z, Moss-Morris R, Hunter M, Hughes L., unpublished data, 2017), which may account for the inconsistent relationship between side effects and adherence.

Being treated by specialists rather than a general practitioner increased persistence. These physicians may provide more specialized and informed care, ${ }^{43}$ leading to women being more educated and having positive treatment beliefs, although this was not measured directly. An intervention focusing on knowledge and beliefs may support women who did not receive this from their physician. This is supported by the studies showing that medication beliefs are related to adherence levels. ${ }^{26,35}$ Furthermore, several studies showed that variables relating to the patient-physician relationship and physician communication were associated with increased odds of adherence. These results suggest that training primary care physicians to provide more specialized care could improve adherence rates.

Some evidence suggested that women whose insurance data indicated nonadherence or nonpersistence over 1-5 years were more likely to have been hospitalized over the same period. These women may have not taken their medication while in hospital, but as no data were provided for adherence levels during the hospitalization, no strong conclusions can be made. There was relatively consistent evidence from moderate- to high-quality studies, suggesting that younger women had lower odds of adherence and slightly less consistent evidence for a relationship between younger age and nonpersistence. This is in line with previous reviews into adherence in cancer and other illnesses. ${ }^{74,75}$ Young women may not take HT due to issues around early menopause or fertility $^{24}$ as HT precludes conception. In addition, young women do not adjust as well to a cancer diagnosis, which may affect adherence. ${ }^{54,76}$ Results were mixed for the relationship between older age and adherence or persistence.

In terms of modifiable factors, three studies found that women who reported few sources of social support were more likely to discontinue treatment. The importance of social support in maintaining adherence has been highlighted previously, ${ }^{77,78}$ but social support was only found to relate to persistence in this review. Discussing the importance of maintaining good social networks and disclosure of cancer status may increase levels of perceived social support. Several studies have shown promise for the effectiveness of social support interventions. ${ }^{79,80}$ Self-efficacy for medication taking, defined as the patient's confidence in their ability to take the medication as prescribed, was associated with increased odds of self-reported adherence. ${ }^{27}$ Self-efficacy for medication taking could be modified by teaching patients strategies to remember to take their medication and helping patients to overcome other practical barriers through modeling, goal setting, or confidence building. Similar interventions have been successful at improving self-efficacy for physical activity and dietary behaviors. ${ }^{81,82}$

Patients who held stronger beliefs regarding how efficacious, necessary, important and affordable HT is were more likely to have higher self-reported adherence, as were women who reported more positive emotions around HT. In addition, women who felt that the risks of the treatment outweighed the benefits were three times more likely to discontinue. This relationship between beliefs and adherence is supported by the Necessity Concerns Framework (NCF) and has been demonstrated previously. ${ }^{83,84}$ The NCF suggests that adherence is related to holding high perceptions of the necessity of the medication and low concerns. These beliefs are often shown to be more powerful predictors of adherence than clinical or sociodemographic characteristics and have been successfully modified through intervention..$^{35,83,85}$ However, the studies investigating beliefs in this review were low- to moderate-quality cross-sectional studies and some used unvalidated measures. In addition, while medication concerns are often found to be predictive of adherence, ${ }^{83}$ the majority of studies found nonsignificant results. This suggests that it may be more important to measure how people weigh up their concerns against their necessity beliefs.

The variability between studies may reflect the heterogeneous populations studied. There were discrepancies in geographic location, health care systems and clinical characteristics. 
Furthermore, while several studies recruited patients at the initiation of treatment, many studies did not specify the stage of treatment. Research has shown that determinants of adherence vary significantly over time. ${ }^{10}$ Therefore, future research should try to recruit patients at the same time point, explicitly state participants' stage of treatment and follow them over the duration of the prescription period.

The results from this review suggest that there are no strong predictors of HT adherence or persistence. Reviewing high-quality studies in isolation $(n=22)$ reflected this pattern of inconsistent results. However, the high-quality studies did support the trend of higher rates of discontinuation in older women and lower adherence in black women, suggesting a need to further investigate these relationships. The majority of predictors investigated, such as age, are not amenable to change through intervention. Future research is needed to identify psychosocial factors that have been shown to impact on adherence in other conditions. For example, illness perceptions have been shown to be predictive of adherence in other illnesses but have not been investigated fully in HT adherence. ${ }^{12,86}$ This review identified one study investigating illness perceptions, which found that coherence beliefs, ie, patients' ratings of their understanding of their breast cancer, were the only significant predictors of nonadherence in multivariate analysis. ${ }^{46}$ Self-efficacy for taking medication, social support and medication beliefs provide potential targets for intervention. However, higher quality research is needed in order to clarify the relationship between medication beliefs and adherence. Interventions could also focus on training clinicians and general practitioners to improve patient-physician communication.

There are several limitations to this review. It was not possible to conduct a meta-analysis due to significant heterogeneity between studies. This heterogeneity also makes it difficult to compare across studies and make conclusions based on significant predictors of nonadherence. Although a wide search was conducted and attempts were made to identify gray literature, some relevant articles may not have been identified. The conclusions are limited by the methodological quality of the included studies. There was a risk of selection bias in some studies, which means a subset of the population who are potentially more at risk of nonadherence may not be included. Sixteen studies were cross-sectional which limits assumptions about causality. Two studies used MEMS to measure adherence and found very high levels, most likely due to the Hawthorne effect where adherence increases because patients know that they are being monitored. ${ }^{87}$ The most common measurement of adherence and persistence was prescription refill, which is known to be the most objective measure. ${ }^{88}$ However, this measurement is still flawed, as we do not know if the patient actually took their medication. Several studies used physician ratings, which are likely to grossly overestimate adherence levels. ${ }^{89}$ Self-report measures are also susceptible to overreporting due to social desirability. Four studies overcame these limitations somewhat by using validated questionnaires.

There are several reasons that a patient may be recommended by their physician to discontinue treatment, such as recurrence and contraindications. These patients should not be classified in the same way as women who choose to discontinue HT and should be removed from analysis. Around a third of studies attempted to adjust for this by removing women who had a recurrence or who died. Seven studies did not allow patients to switch medications and still be considered persistent, and 13 studies were unclear as to whether they allowed this. Furthermore, only a few studies have clearly distinguished between nonadherence and nonpersistence and provided independent figures for both. Without this information, it is not possible to determine the full medication-taking behavior of these patients and, therefore, the clinical impact. The behaviors and outcomes of completely stopping treatment and occasionally skipping doses are different, so it is important to understand these as independent with unique predictors. Future research needs to be clear about how nonadherence rates are classified and ideally to provide independent rates for nonadherence and nonpersistence.

\section{Conclusion}

Understanding the determinants of nonadherence is essential when designing interventions to improve HT adherence and ensuring that patients realize the full benefits of HT. The main conclusions that can be drawn from this review are that while clinical and demographic factors may be useful in order to identify women at risk of nonadherence, extensive research has not yet identified any consistent predictors. There was some evidence that increased adherence was related to younger age, fewer hospitalizations and better patient-physician relationship, but these relationships were not always supported. Persistence was related to receiving treatment from a specialist. In terms of modifiable factors, there was some evidence to suggest that beliefs about HT, social support and self-efficacy for taking medication were related to adherence and persistence. In order to guide effective interventions to improve HT adherence and persistence, future research should focus on these factors and on identifying additional 
potentially modifiable factors, which have been shown to be related to adherence in other illnesses. ${ }^{13}$ Furthermore, strategies to improve patient-physician relationship and service delivery should be investigated.

\section{Acknowledgment}

This study was supported by Breast Cancer Now (formally Breast Cancer Campaign) under grant number: 2013NovPhD201.

\section{Disclosure}

The authors report no conflicts of interest in this work.

\section{References}

1. Breast Cancer Statistics [webpage on the Internet]. Cancer Research UK Web Site; 2016. Available from: http://www.cancerresearchuk. org/health-professional/cancer-statistics/statistics-by-cancer-type/ breast-cancer. Accessed October 10, 2016.

2. Gray RG, Rea D, Handley K, et al. ATTom: long-term effects of continuing adjuvant tamoxifen to 10 years versus stopping at 5 years in 6,953 women with early breast cancer. J Clin Oncol. 2013;18(31):5.

3. Early Breast Cancer Trialists' Collaborative Group. Tamoxifen for early breast cancer: an overview of the randomised trials. Early Breast Cancer Trialists' Collaborative Group. Lancet. 1998;351(9114):1451-1467.

4. Barron TI, Cahir C, Sharp L, Bennett K. A nested case-control study of adjuvant hormonal therapy persistence and compliance, and early breast cancer recurrence in women with stage I-III breast cancer. Br J Cancer. 2013;109(6):1513-1521.

5. Hershman DL, Shao T, Kushi LH, et al. Early discontinuation and nonadherence to adjuvant hormonal therapy are associated with increased mortality in women with breast cancer. Breast Cancer Res Treat. 2011; 126(2):529-537.

6. Makubate B, Donnan PT, Dewar JA, Thompson AM, McCowan C. Cohort study of adherence to adjuvant endocrine therapy, breast cancer recurrence and mortality. Br J Cancer. 2013;108(7):1515-1524.

7. Huiart L, Bouhnik A-D, Rey D, et al. Complementary or alternative medicine as possible determinant of decreased persistence to aromatase inhibitor therapy among older women with non-metastatic breast cancer. PLoS One. 2013;8(12):e81677.

8. Hershman DL, Kushi LH, Shao T, et al. Early discontinuation and nonadherence to adjuvant hormonal therapy in a cohort of 8,769 earlystage breast cancer patients. J Clin Oncol. 2010;28(27):4120-4128.

9. Partridge AH, Wang PS, Winer EP, Avorn J. Nonadherence to adjuvant tamoxifen therapy in women with primary breast cancer. $J$ Clin Oncol. 2003;21(4):602-606.

10. Cluze C, Rey D, Huiart L, et al. Adjuvant endocrine therapy with tamoxifen in young women with breast cancer: determinants of interruptions vary over time. Ann Oncol. 2012;23(4):882-890.

11. Owusu C, Buist DS, Field TS, et al. Predictors of tamoxifen discontinuation among older women with estrogen receptor-positive breast cancer. J Clin Oncol. 2008;26(4):549-555.

12. Horne R, Weinman J. Self-regulation and self-management in asthma: exploring the role of illness perceptions and treatment beliefs in explaining non-adherence to preventer medication. Psychol Health. 2002;17(1):17-32.

13. Chilcot J, Wellsted D, Farrington K. Illness representations are associated with fluid nonadherence among hemodialysis patients. J Psychosom Res. 2010;68(2):203-212.

14. Goulding L, Furze G, Birks Y. Randomized controlled trials of interventions to change maladaptive illness beliefs in people with coronary heart disease: systematic review. J Adv Nurs. 2010;66(5):946-961.
15. Petrie KJ, Perry K, Broadbent E, Weinman J. A text message programme designed to modify patients' illness and treatment beliefs improves self-reported adherence to asthma preventer medication. Br J Health Psychol. 2012;17(1):74-84.

16. Murphy CC, Bartholomew LK, Carpentier MY, Bluethmann SM, Vernon SW. Adherence to adjuvant hormonal therapy among breast cancer survivors in clinical practice: a systematic review. Breast Cancer Res Treat. 2012;134(2):459-478.

17. Cahir C, Guinan E, Dombrowski SU, Sharp L, Bennett K. Identifying the determinants of adjuvant hormonal therapy medication taking behaviour in women with stages I-III breast cancer: a systematic review and meta-analysis. Patient Educ Couns. Epub 2015 May 30.

18. Van Liew JR, Christensen AJ, de Moor JS. Psychosocial factors in adjuvant hormone therapy for breast cancer: an emerging context for adherence research. J Cancer Surviv. 2014;8(3):521-531.

19. Liberati A, Altman DG, Tetzlaff J, et al. The PRISMA statement for reporting systematic reviews and meta-analyses of studies that evaluate healthcare interventions: explanation and elaboration. $B M J$. 2009;339:b2700.

20. McCowan C, Wang S, Thompson AM, Makubate B, Petrie DJ. The value of high adherence to tamoxifen in women with breast cancer: a community-based cohort study. Br J Cancer. 2013;109(5): $1172-1180$.

21. Pasma A, van't Spijker A, Hazes JMW, Busschbach JJV, Luime JJ. Factors associated with adherence to pharmaceutical treatment for rheumatoid arthritis patients: a systematic review. Semin Arthritis Rheum. 2013;43(1):18-28.

22. Sanderson S, Tatt ID, Higgins JP. Tools for assessing quality and susceptibility to bias in observational studies in epidemiology: a systematic review and annotated bibliography. Int J Epidemiol. 2007;36(3): 666-676.

23. Brito C, Portela MC, de Vasconcellos MTL. Adherence to hormone therapy among women with breast cancer. BMC Cancer. 2014;14(1):397.

24. Brito C, Portela MC, Leite de Vasconcellos MT. Factors associated to persistence with hormonal therapy in women with breast cancer. Rev Saude Publica. 2014;48(2):284-295.

25. Lash TL, Fox MP, Westrup JL, Fink AK, Silliman RA. Adherence to tamoxifen over the five-year course. Breast Cancer Res Treat. 2006; 99(2):215-220.

26. Fink AK, Gurwitz J, Rakowski W, Guadagnoli E, Silliman RA. Patient beliefs and tamoxifen discontinuance in older women with estrogen receptor-positive breast cancer. J Clin Oncol. 2004;22(16):3309-3315.

27. Kimmick G, Edmond SN, Bosworth HB, et al. Medication taking behaviors among breast cancer patients on adjuvant endocrine therapy. Breast. 2015;24(5):630-636.

28. Tinari N, Fanizza C, Romero M, et al. Identification of subgroups of early breast cancer patients at high risk of nonadherence to adjuvant hormone therapy: results of an Italian survey. Clin Breast Cancer. 2015;15(2): e131-e137.

29. Wouters H, Stiggelbout AM, Bouvy ML, et al. Endocrine therapy for breast cancer: assessing an array of women's treatment experiences and perceptions, their perceived self-efficacy and nonadherence. Clin Breast Cancer. 2014;14(6):460-467.e2.

30. Hershman DL, Tsui J, Meyer J, et al. The change from brand-name to generic aromatase inhibitors and hormone therapy adherence for early-stage breast cancer. J Natl Cancer Inst. 2014;106(11):dju319.

31. Hershman DL, Tsui J, Wright JD, Coromilas EJ, Tsai WY, Neugut AI. Household net worth, racial disparities, and hormonal therapy adherence among women with early-stage breast cancer. J Clin Oncol. 2015;33(9):1053-1059.

32. Neugut AI, Subar M, Wilde ET, et al. Association between prescription co-payment amount and compliance with adjuvant hormonal therapy in women with early-stage breast cancer. J Clin Oncol. 2011; 29(18):2534-2542.

33. Lee HS, Lee JY, Ah YM, et al. Low adherence to upfront and extended adjuvant letrozole therapy among early breast cancer patients in a clinical practice setting. Oncology. 2014;86(5-6):340-349. 
34. Sedjo RL, Devine S. Predictors of non-adherence to aromatase inhibitors among commercially insured women with breast cancer. Breast Cancer Res Treat. 2011;125(1):191-200.

35. Stanton AL, Petrie KJ, Partridge AH. Contributors to nonadherence and nonpersistence with endocrine therapy in breast cancer survivors recruited from an online research registry. Breast Cancer Res Treat. 2014; 145(2):525-534.

36. Trabulsi N, Reidel KE, Winslade NE, et al. Adherence to anti-estrogen therapy in seniors with breast cancer: how well are we doing? Breast J. 2014;20(6):632-638.

37. Wigertz A, Ahlgren J, Holmqvist M, et al. Adherence and discontinuation of adjuvant hormonal therapy in breast cancer patients: a populationbased study. Breast Cancer Res Treat. 2012;133(1):367-373.

38. Font R, Espinas JA, Gil-Gil M, et al. Prescription refill, patient selfreport and physician report in assessing adherence to oral endocrine therapy in early breast cancer patients: a retrospective cohort study in Catalonia, Spain. Br J Cancer. 2012;107(8):1249-1256.

39. Hsieh K-P, Chen L-C, Cheung K-L, Yang Y-H. Risks of nonadherence to hormone therapy in Asian women with breast cancer. Kaohsiung $J$ Med Sci. 2015;31(6):328-334.

40. Bender CM, Gentry AL, Brufsky AM, et al. Influence of patient and treatment factors on adherence to adjuvant endocrine therapy in breast cancer. Oncol Nurs Forum. 2014;41(3):274-285.

41. Wickersham KE, Sereika SM, Bender CM. Pretreatment predictors of short-term nonadherence to oral hormonal therapy for women with breast cancer. Nurs Res. 2013;62(4):243-251.

42. Schover LR, Baum GP, Fuson LA, Brewster A, Melhem-Bertrandt A Sexual problems during the first 2 years of adjuvant treatment with aromatase inhibitors. J Sex Med. 2014;11(12):3102-3111.

43. Hadji P, Ziller V, Kyvernitakis J, et al. Persistence in patients with breast cancer treated with tamoxifen or aromatase inhibitors: a retrospective database analysis. Breast Cancer Res Treat. 2013;138(1):185-191.

44. Kostev K, Waehlert L, Jockwig A, Jockwig B, Hadji P. Physicians' influence on breast cancer patient compliance. Ger Med Sci. 2014;12:Doc03.

45. Kostev K, May U, Hog D, et al. Adherence in tamoxifen therapy after conversion to a rebate pharmaceutical in breast cancer patients in Germany. Int J Clin Pharmacol Ther. 2013;51(12):969-975.

46. Corter AL. Treatment Side Effects and Nonadherence among Women Taking Adjuvant Endocrine Therapy for Breast Cancer: The Role of Psychological Factors [PhD thesis]. Auckland: The University of Auckland; 2013.

47. Demissie S, Silliman RA, Lash TL. Adjuvant tamoxifen: predictors of use, side effects, and discontinuation in older women. J Clin Oncol. 2001;19(2):322-328.

48. Kahn KL, Schneider EC, Malin JL, Adams JL, Epstein AM. Patient centered experiences in breast cancer - predicting long-term adherence to tamoxifen use. Med Care. 2007;45(5):431-439.

49. Kemp A, Preen DB, Saunders C, et al. Early discontinuation of endocrine therapy for breast cancer: who is at risk in clinical practice? Springerplus. 2014;3:282.

50. Liu Y, Malin JL, Diamant AL, Thind A, Maly RC. Adherence to adjuvant hormone therapy in low-income women with breast cancer: the role of provider-patient communication. Breast Cancer Res Treat. 2013;137(3): 829-836.

51. Aiello Bowles EJ, Boudreau DM, Chubak J, et al. Patient-reported discontinuation of endocrine therapy and related adverse effects among women with early-stage breast cancer. J Oncol Pract. 2012;8(6): e149-e157.

52. Riley GF, Warren JL, Harlan LC, Blackwell SA. Endocrine therapy use among elderly hormone receptor-positive breast cancer patients enrolled in Medicare Part D. Medicare Medicaid Res Rev. 2011;1(4).

53. Guth U, Myrick ME, Kilic N, Eppenberger-Castori S, Schmid SM. Compliance and persistence of endocrine adjuvant breast cancer therapy. Breast Cancer Res Treat. 2012;131(2):491-499.

54. Barron TI, Connolly R, Bennett K, Feely J, Kennedy MJ. Early discontinuation of tamoxifen: a lesson for oncologists. Cancer. 2007;109(5): 832-839.
55. Friese CR, Pini TM, Li Y, et al. Adjuvant endocrine therapy initiation and persistence in a diverse sample of patients with breast cancer. Breast Cancer Res Treat. 2013;138(3):931-939.

56. Krotneva SP, Ramjaun A, Reidel KE, et al. Use of hormonal therapy in senior breast cancer patients treated with or without radiotherapy. Curr Oncol. 2014;21(1):e105-e115.

57. Nekhlyudov L, Li L, Ross-Degnan D, Wagner AK. Five-year patterns of adjuvant hormonal therapy use, persistence, and adherence among insured women with early-stage breast cancer. Breast Cancer Res Treat. 2011;130(2):681-689.

58. Wu J, Stafkey-Mailey D, Bennett CL. Long-term adherence to hormone therapy in medicaid-enrolled women with breast cancer. Health Outcomes Res Med. 2012;3(4):e195-e203.

59. Seneviratne S, Campbell I, Scott N, et al. Adherence to adjuvant endocrine therapy: is it a factor for ethnic differences in breast cancer outcomes in New Zealand? Breast. 2015;24(1):62-67.

60. Schmidt N, Kostev K, Jockwig A, Kyvernitakis I, Albert US, Hadji P. Treatment persistence evaluation of tamoxifen and aromatase inhibitors in breast cancer patients in early and late stage disease. Int J Clin Pharmacol Ther. 2014;52(11):933-939.

61. Bhatta SS, Hou N, Moton ZN, et al. Factors associated with compliance to adjuvant hormone therapy in Black and White women with breast cancer. Springerplus. 2013;2:356.

62. He W, Fang F, Varnum C, Eriksson M, Hall P, Czene K. Predictors of discontinuation of adjuvant hormone therapy in patients with breast cancer. J Clin Oncol. 2015;33(20):2262-2269.

63. van Herk-Sukel MP, van de Poll-Franse LV, Voogd AC, Nieuwenhuijzen GA, Coebergh JW, Herings RM. Half of breast cancer patients discontinue tamoxifen and any endocrine treatment before the end of the recommended treatment period of 5 years: a population-based analysis. Breast Cancer Res Treat. 2010;122(3): 843-851.

64. Sheppard VB, Faul LA, Luta G, et al. Frailty and adherence to adjuvant hormonal therapy in older women with breast cancer: CALGB protocol 369901. J Clin Oncol. 2014;32(22):2318-2327.

65. Llarena NC, Estevez SL, Tucker SL, Jeruss JS. Impact of fertility concerns on tamoxifen initiation and persistence. J Natl Cancer Inst. 2015; 107(10):djv202.

66. Grunfeld EA, Hunter MS, Sikka P, Mittal S. Adherence beliefs among breast cancer patients taking tamoxifen. Patient Educ Couns. 2005;59(1): 97-102.

67. Jacob Arriola KR, Mason TA, Bannon KA, et al. Modifiable risk factors for adherence to adjuvant endocrine therapy among breast cancer patients. Patient Educ Couns. 2014;95(1):98-103.

68. Walker HE, Rosenberg SM, Stanton AL, Petrie KJ, Partridge AH. Perceptions, attributions, and emotions toward endocrine therapy in young women with breast cancer. J Adolesc Young Adult Oncol. 2016; 5(1):16-23.

69. Karmakar M. Predicting Adherence to Aromatase Inhibitor Therapy in Patients with Breast Cancer Using Protection Motivation Theory [PhD thesis]. Toledo: The University of Toledo; 2013.

70. Huiart L, Bouhnik AD, Rey D, et al. Early discontinuation of tamoxifen intake in younger women with breast cancer: is it time to rethink the way it is prescribed? Eur J Cancer. 2012;48(13): 1939-1946.

71. Gotay C, Dunn J. Adherence to long-term adjuvant hormonal therapy for breast cancer. Expert Rev Pharmacoecon Outcomes Res. 2011; 11(6):709-715.

72. Wheeler SB, Roberts MC, Bloom D, et al. Oncology providers' perspectives on endocrine therapy prescribing and management. Patient Prefer Adherence. 2016;10:2007-2019.

73. Hogan BE, Linden W, Najarian B. Social support interventions: do they work? Clin Psychol Rev. 2002;22(3):383-442.

74. Verbrugghe M, Verhaeghe S, Lauwaert K, Beeckman D, Van Hecke A. Determinants and associated factors influencing medication adherence and persistence to oral anticancer drugs: a systematic review. Cancer Treat Rev. 2013;39(6):610-621. 
75. Barr R, Somers SC, Speizer FE, Camargo CA Jr; National Asthma Education and Prevention Program (NAEPP). Patient factors and medication guideline adherence among older women with asthma. Arch Inten Med. 2002;162(15):1761-1768.

76. Compas BE, Stoll MF, Thomsen AH, Oppedisano G, Epping-Jordan JE, Krag DN. Adjustment to breast cancer: age-related differences in coping and emotional distress. Breast Cancer Res Treat. 1999;54(3): 195-203.

77. Partridge AH, Avorn J, Wang PS, Winer EP. Adherence to therapy with oral antineoplastic agents. J Natl Cancer Inst. 2002;94(9):652-661.

78. Knodel J, Kespichayawattana J, Saengtienchai C, Wiwatwanich S. The role of parents and family members in ART treatment adherence: evidence from Thailand. Res Aging. 2010;32(1):19-39.

79. Barrera M, Glasgow RE, McKay HG, Boles SM, Feil EG. Do internet-based support interventions change perceptions of social support?: an experimental trial of approaches for supporting diabetes self-management. Am J Community Psychol. 2002;30(5):637-654.

80. Czechura T, Winchester DJ, Pesce C, Barrera E, Winchester DP, Yao K. Impact of bilateral versus unilateral mastectomy on short term outcome and adjuvant therapy. Ann Surg Oncol. 2013;1:S49.

81. Ashford S, Edmunds J, French DP. What is the best way to change self-efficacy to promote lifestyle and recreational physical activity? A systematic review with meta-analysis. Br J Health Psychol. 2010; 15(2):265-288.

82. Prestwich A, Kellar I, Parker R, et al. How can self-efficacy be increased? Meta-analysis of dietary interventions. Health Psychol Rev. 2014;8(3):270-285.

83. Horne R, Weinman J. Patients' beliefs about prescribed medicines and their role in adherence to treatment in chronic physical illness. J Psychosom Res. 1999;47(6):555-567.

84. Clatworthy J, Bowskill R, Parham R, Rank T, Scott J, Horne R. Understanding medication non-adherence in bipolar disorders using a Necessity-Concerns Framework. J Affect Disord. 2009;116(1-2): $51-55$.

85. O'Carroll RE, Chambers JA, Dennis M, Sudlow C, Johnston M. Improving adherence to medication in stroke survivors: a pilot randomised controlled trial. Ann Behav Med. 2013;46(3):358-368.
86. Byer B, Myers LB. Psychological correlates of adherence to medication in asthma. Psychol Health Med. 2000;5(4):389-393.

87. Wetzels GE, Nelemans PJ, Schouten JS, van Wijk BL, Prins MH. All that glisters is not gold: a comparison of electronic monitoring versus filled prescriptions - an observational study. BMC Health Serv Res. 2006;6:8.

88. Ruddy K, Mayer E, Partridge A. Patient adherence and persistence with oral anticancer treatment. CA Cancer J Clin. 2009;59(1):56-66.

89. Oberguggenberger AS, Sztankay M, Beer B, et al. Adherence evaluation of endocrine treatment in breast cancer: methodological aspects. $B M C$ Cancer. 2012;12:474.

90. Cheung WY, Lai EC-C, Ruan JY, Chang JT, Setoguchi S. Comparative adherence to oral hormonal agents in older women with breast cancer. Breast Cancer Res Treat. 2015;152(2):419-427.

91. Danilak M, Chambers CR. Adherence to adjuvant endocrine therapy in women with breast cancer. J Oncol Pharm Pract. 2013;19(2): 105-110.

92. Kimmick G, Anderson R, Camacho F, Bhosle M, Hwang W, Balkrishnan R. Adjuvant hormonal therapy use among insured, low-income women with breast cancer. J Clin Oncol. 2009;27(21):3445-3451.

93. Kuba S, Ishida M, Shigechi T, et al. Persistence and discontinuation of adjuvant endocrine therapy in Japanese women with breast cancer. Breast Cancer. 2016;23(1):128-133.

94. Livaudais JC, LaCroix A, Chlebowski RT, et al. Racial/ethnic differences in use and duration of adjuvant hormonal therapy for breast cancer in the women's health initiative. Cancer Epidemiol Biomarkers Prev. 2012;22:365-373.

95. Simon R, Latreille J, Matte C, Desjardins P, Bergeron E. Adherence to adjuvant endocrine therapy in estrogen receptor-positive breast cancer patients with regular follow-up. Can J Surg. 2014;57(1):26-32.

96. Ziller V, Kalder M, Albert US, et al. Adherence to adjuvant endocrine therapy in postmenopausal women with breast cancer. Ann Oncol. 2009;20(3):431-436.

97. Zeeneldin AA, Gaber AA, Taha FM. Does fasting during Ramadan trigger non-adherence to oral hormonal therapy in breast cancer patients? J Egypt Natl Canc Inst. 2012;24(3):133-137.
Patient Preference and Adherence

\section{Publish your work in this journal}

Patient Preference and Adherence is an international, peer-reviewed, open access journal that focuses on the growing importance of patient preference and adherence throughout the therapeutic continuum. Patient satisfaction, acceptability, quality of life, compliance, persistence and their role in developing new therapeutic modalities and compounds to optimize

\section{Dovepress}

clinical outcomes for existing disease states are major areas of interest for the journal. This journal has been accepted for indexing on PubMed Central. The manuscript management system is completely online and includes a very quick and fair peer-review system, which is all easy to use. Visit http://www dovepress.com/testimonials.php to read real quotes from published authors. 